University of Tennessee Health Science Center

UTHSC Digital Commons

\title{
Predictors of Quality of Life for African American Women Who Assist Persons Who Receive Dialysis
}

Shaquita A. Starks

University of Tennessee Health Science Center

Follow this and additional works at: https://dc.uthsc.edu/dissertations

Part of the Demography, Population, and Ecology Commons, Inequality and Stratification Commons, Medicine and Health Commons, Psychological Phenomena and Processes Commons, and the Race and Ethnicity Commons

\section{Recommended Citation}

Starks, Shaquita A. (http://orcid.org/0000-0002-1117-5485), "Predictors of Quality of Life for African American Women Who Assist Persons Who Receive Dialysis" (2016). Theses and Dissertations (ETD). Paper 395. http://dx.doi.org/10.21007/etd.cghs.2016.0398.

This Dissertation is brought to you for free and open access by the College of Graduate Health Sciences at UTHSC Digital Commons. It has been accepted for inclusion in Theses and Dissertations (ETD) by an authorized administrator of UTHSC Digital Commons. For more information, please contact jwelch30@uthsc.edu. 


\title{
Predictors of Quality of Life for African American Women Who Assist Persons Who Receive Dialysis
}

\begin{abstract}
The purpose of this predictive correlational study was to describe predictors of quality of life (QoL) for African American women who were caregivers of persons with end stage renal disease (ESRD). Five purposes, derived from a review of literature and conceptual model, guided this study. First, the study described the association between demographic factors (i.e., education, employment, age, marital status), and QoL. Second, the study explored the relationship between stress and QoL. Third, the study described the association between depressive symptoms and QoL. Fourth, the study described the association between family health/happiness and QoL. Fifth, the study described the extent to which demographic factors, stress, depressive symptoms, and family health/happiness predicted QoL. A secondary analysis of data from 75 African American women derived from a previous study of 120 caregivers of persons receiving either maintenance in-center hemodialysis or home peritoneal dialysis was conducted. Specifically data from the following instruments were included in the current analysis: The Caregiver Demographic Data Form, Quality of Life Index, Family APGAR, Burden Interview, and the Center for Epidemiological Studies Depression Scale (CES-D). Data were analyzed using descriptive statistics, Pearson's r coefficient one -way ANOVA on ranks (Kruskal-Wallis), independent t-test, and backward elimination, forward selection, and step-type multiple regression analysis. The caregivers in this sample rated their QoL as moderate. Caregivers also reported clinically significant depressive symptom scores, little to no stress, and were satisfied with their family health/happiness. Significant negative correlations were found between hours worked, education, stress, and QoL. Significant positive relationships were found between age, educational level, recipients' relationship to the caregiver, family health/happiness, satisfaction with support, and QoL. Four variables-education, full time employment, part time employment, marital status, and stress-explained $63 \%$ of the total variance in QoL scores $(p<$ 0.0001). Caregivers who had more education, were employed full time or part time, and reported more stress experienced the lowest QoL. In addition, caregivers who were married experienced the highest QoL. The findings of this study suggest that QoL is multifaceted and is affected by many areas of a person's life. Social and economic factors and stress were the strongest predictors of QoL for African American women caring for persons with ESRD. The African American women in this study did not experience high levels of stress even though stress was a significant predictor of QoL. This finding may reflect a problem with the measurement of stress used in this population. Several factors, including caregiver work status, explained caregivers' QoL. Findings from this study provide support for exploring the needs of working caregivers, as QoL was lowest in this group. Understanding better the experiences of working caregivers would inform clinical practice, health policies, and theory development that address the needs of understudied African American women who help persons manage ESRD.
\end{abstract}

\section{Document Type}

Dissertation

\section{Degree Name}

Doctor of Philosophy (PhD)

\section{Program}

Nursing Science

Research Advisor

Mona Newsome-Wicks, Ph.D., RN 


\section{Keywords}

African American, Caregiver, End Stage Renal Disease, Predictors, Quality of life, Women

\section{Subject Categories}

Demography, Population, and Ecology | Inequality and Stratification | Medicine and Health | Medicine and Health Sciences | Psychiatry and Psychology | Psychological Phenomena and Processes | Race and Ethnicity

\section{Comments}

The purpose of this predictive correlational study was to describe predictors of quality of life (QoL) for African American women who were caregivers of persons with end stage renal disease (ESRD). Five purposes, derived from a review of literature and conceptual model, guided this study. First, the study described the association between demographic factors (i.e., education, employment, age, marital status), and QoL. Second, the study explored the relationship between stress and QoL. Third, the study described the association between depressive symptoms and QoL. Fourth, the study described the association between family health/happiness and QoL. Fifth, the study described the extent to which demographic factors, stress, depressive symptoms, and family health/happiness predicted QoL. A secondary analysis of data from 75 African American women derived from a previous study of 120 caregivers of persons receiving either maintenance in-center hemodialysis or home peritoneal dialysis was conducted. Specifically data from the following instruments were included in the current analysis: The Caregiver Demographic Data Form, Quality of Life Index, Family APGAR, Burden Interview, and the Center for Epidemiological Studies Depression Scale (CES-D). Data were analyzed using descriptive statistics, Pearson's r coefficient one -way ANOVA on ranks (Kruskal-Wallis), independent t-test, and backward elimination, forward selection, and step-type multiple regression analysis. The caregivers in this sample rated their QoL as moderate. Caregivers also reported clinically significant depressive symptom scores, little to no stress, and were satisfied with their family health/happiness. Significant negative correlations were found between hours worked, education, stress, and QoL. Significant positive relationships were found between age, educational level, recipients' relationship to the caregiver, family health/happiness, satisfaction with support, and QoL. Four variables-education, full time employment, part time employment, marital status, and stress-explained $63 \%$ of the total variance in QoL scores $(p<$ 0.0001). Caregivers who had more education, were employed full time or part time, and reported more stress experienced the lowest QoL. In addition, caregivers who were married experienced the highest QoL. The findings of this study suggest that QoL is multifaceted and is affected by many areas of a person's life. Social and economic factors and stress were the strongest predictors of QoL for African American women caring for persons with ESRD. The African American women in this study did not experience high levels of stress even though stress was a significant predictor of QoL. This finding may reflect a problem with the measurement of stress used in this population. Several factors, including caregiver work status, explained caregivers' QoL. Findings from this study provide support for exploring the needs of working caregivers, as QoL was lowest in this group. Understanding better the experiences of working caregivers would inform clinical practice, health policies, and theory development that address the needs of understudied African American women who help persons manage ESRD. 


\title{
Predictors of Quality of Life for African American Women Who Assist Persons Who Receive Dialysis
}

\author{
A Dissertation \\ Presented for \\ The Graduate Studies Council \\ The University of Tennessee \\ Health Science Center \\ In Partial Fulfillment \\ Of the Requirements for the Degree \\ Doctor of Philosophy \\ From The University of Tennessee
}

By

Shaquita A. Starks

May 2016 
Copyright $(\mathcal{} 2016$ by Shaquita A Starks.

All rights reserved. 


\section{DEDICATION}

First, I dedicate this dissertation to my "mama", Rosie Wilson, who solely cared for my siblings and me, helped us with our children, and cared for her mother who passed away from complications of end-stage renal disease. I would also like to dedicate this dissertation to my "grandma" Minnie Mae Hale, who tirelessly worked and cared for "non-family" members most of her life. I dedicate this dissertation to my "other grandmother," Olivia "Mama Olivey" Stewart, who not only cared for her children and grandchildren, but who also cared for every child (and adult if they needed help) in our community. I dedicate this dissertation to my "creative grandmother," Miki "Gran-Gran" Hooper, who was a poet and creative writer - she nurtured, loved, motivated, taught, and encouraged many local poets and creative artists in the Memphis metropolitan region. I also dedicate this work to my "spiritual sister," Tiffany "Yasmun" Jones, who made a premature transition from this life. As the big sister, I never had, "Mun" taught me how to dance and how to embrace and honor my femininity. I love you and miss you. Lastly, I dedicate this to all the Black mothers in the world. Many Black women I know do not often share "blood" with those of whom they care for, but they care for them as if they do share "blood." I see what Black women do, how their needs have been neglected, how their voices remain unheard, and all they have been through. I dedicate this dissertation to all Black women in hopes that they will begin to care for themselves as much as they often care for others. Ase.' 


\section{ACKNOWLEDGEMENTS}

I would like to thank my dissertation chair, Dr. Mona N. Wicks, for her mentorship, motivation, and guidance. Additionally, I would like to express my sincerest gratitude to the other members of my dissertation committee, Dr. Wendy Likes, Dr. Carolyn Graff, Dr. Shelly White-Means, Mr. George Relyea, and Dr. Zandria Robinson for their expertise, resources, support, motivation, and guidance through this journey. The mentorship and support I received from my chair and committee members have been invaluable. Lastly, I want to acknowledge Dr. Otis Anderson of First Counseling, Inc., and both Janet Jackson and Dr. Yarandi of the American Nurses Association Minority Fellowship Program, for their added support, encouragement, and assistance throughout my program.

Funding for this dissertation was made possible in part by Grant Number 2T06SM060559-04 or from SAMHSA. The views expressed in written training materials or publications and by speakers and moderators do not necessarily reflect the official policies of the Department of Health and Human Services; nor does mention of trade names, commercial practices, or organizations imply endorsement by the U.S. government. 


\begin{abstract}
The purpose of this predictive correlational study was to describe predictors of quality of life (QoL) for African American women who were caregivers of persons with end stage renal disease (ESRD). Five purposes, derived from a review of literature and conceptual model, guided this study. First, the study described the association between demographic factors (i.e., education, employment, age, marital status), and QoL. Second, the study explored the relationship between stress and QoL. Third, the study described the association between depressive symptoms and QoL. Fourth, the study described the association between family health/happiness and QoL. Fifth, the study described the extent to which demographic factors, stress, depressive symptoms, and family health/happiness predicted QoL. A secondary analysis of data from 75 African American women derived from a previous study of 120 caregivers of persons receiving either maintenance in-center hemodialysis or home peritoneal dialysis was conducted. Specifically data from the following instruments were included in the current analysis: The Caregiver Demographic Data Form, Quality of Life Index, Family APGAR, Burden Interview, and the Center for Epidemiological Studies Depression Scale (CES-D). Data were analyzed using descriptive statistics, Pearson's r coefficient one -way ANOVA on ranks (Kruskal-Wallis), independent t-test, and backward elimination, forward selection, and step-type multiple regression analysis. The caregivers in this sample rated their QoL as moderate. Caregivers also reported clinically significant depressive symptom scores, little to no stress, and were satisfied with their family health/happiness. Significant negative correlations were found between hours worked, education, stress, and QoL. Significant positive relationships were found between age, educational level, recipients' relationship to the caregiver, family health/happiness, satisfaction with support, and QoL. Four variables - education, full time employment, part time employment, marital status, and stress-explained 63\% of the total variance in QoL scores $(p<0.0001)$. Caregivers who had more education, were employed full time or part time, and reported more stress experienced the lowest QoL. In addition, caregivers who were married experienced the highest QoL. The findings of this study suggest that QoL is multifaceted and is affected by many areas of a person's life. Social and economic factors and stress were the strongest predictors of QoL for African American women caring for persons with ESRD. The African American women in this study did not experience high levels of stress even though stress was a significant predictor of QoL. This finding may reflect a problem with the measurement of stress used in this population. Several factors, including caregiver work status, explained caregivers' QoL. Findings from this study provide support for exploring the needs of working caregivers, as QoL was lowest in this group. Understanding better the experiences of working caregivers would inform clinical practice, health policies, and theory development that address the needs of understudied African American women who help persons manage ESRD.
\end{abstract}




\section{TABLE OF CONTENTS}

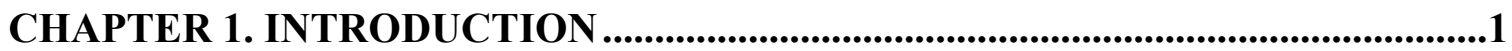

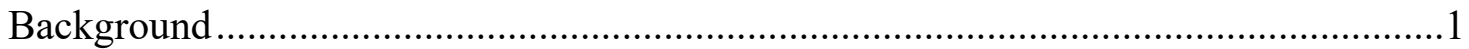

Significance of the Problem ................................................................................

\section{CHAPTER 2. QUALITY OF LIFE OF AFRICAN AMERICAN WOMEN}

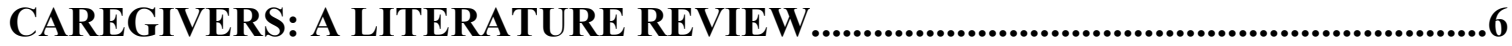

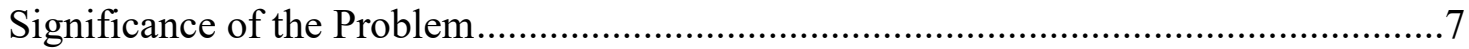

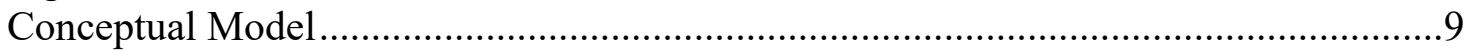

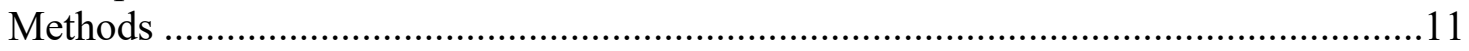

Health and Functioning and Quality of Life ........................................................... 11

Usefulness to Others, Fatigue, Own Health.........................................................13

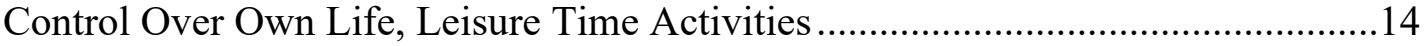

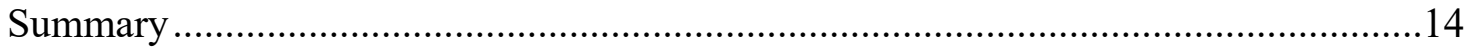

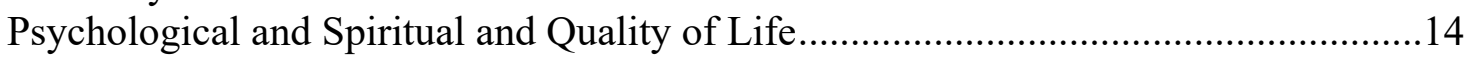

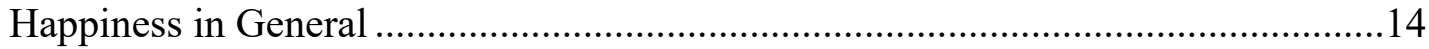

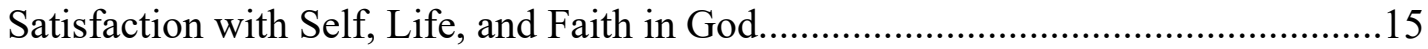

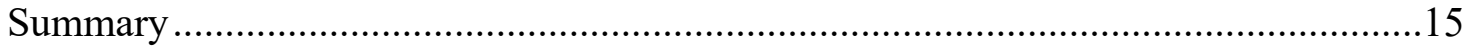

Social and Economic and Quality of Life............................................................... 16

Job/Employment, Education, Financial Independence ...........................................16

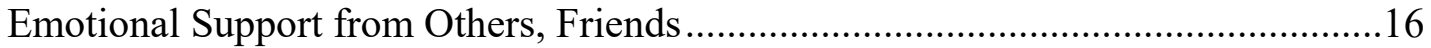

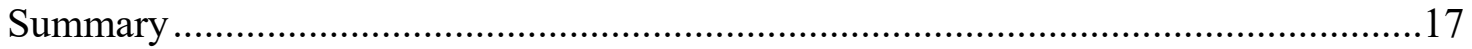

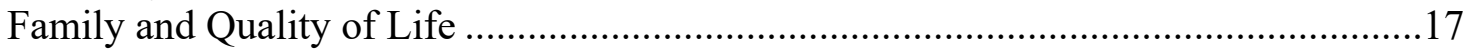

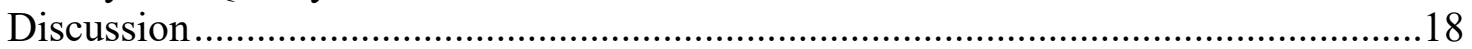

Implications for Future Research..................................................................... 18

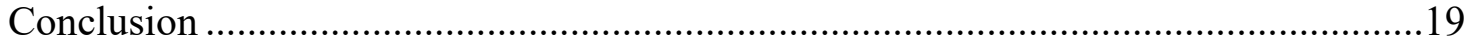

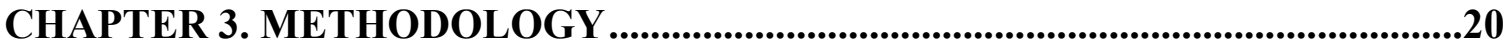

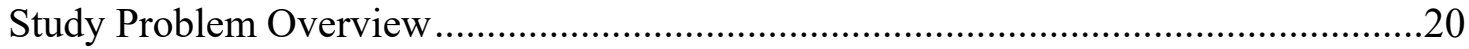

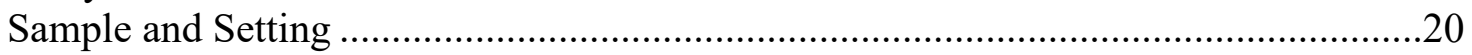

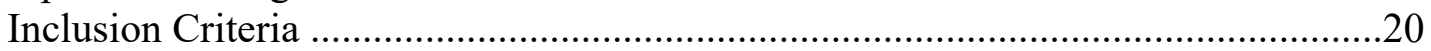

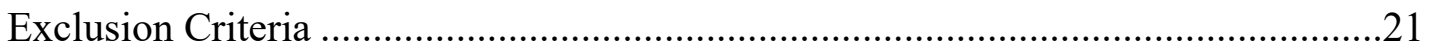

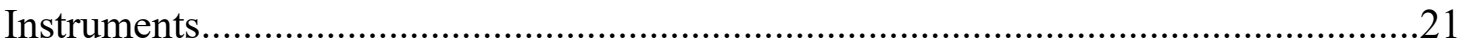

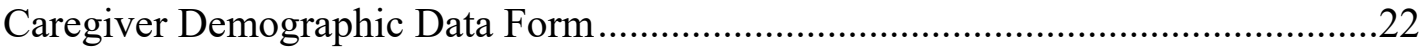

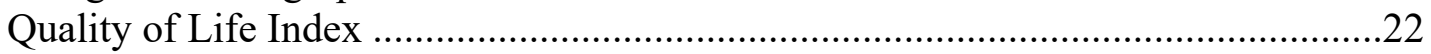

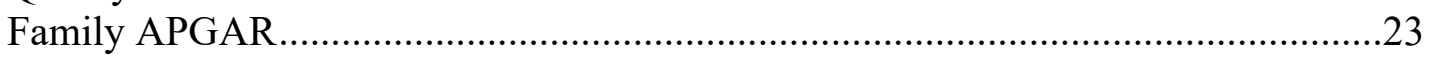

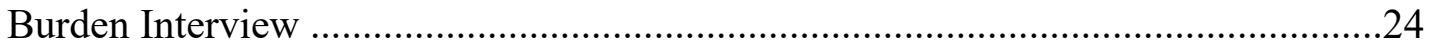

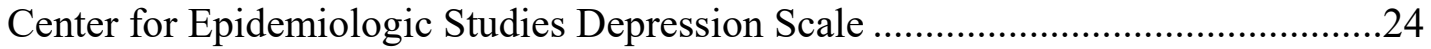

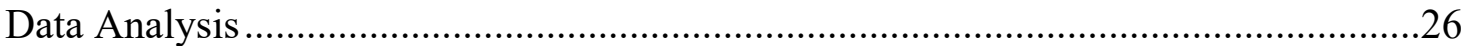

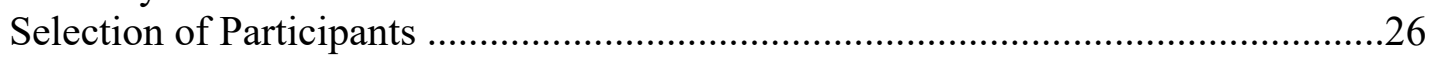

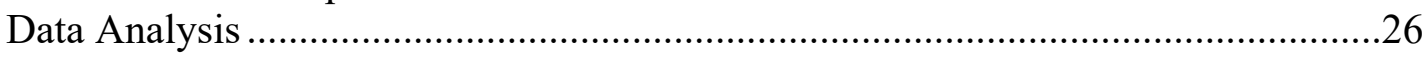

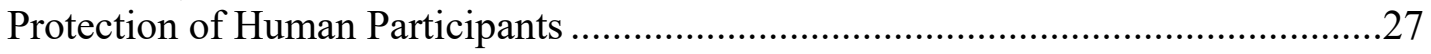




\section{CHAPTER 4. PREDICTORS OF QUALITY OF LIFE IN AFRICAN AMERICAN WOMEN WHO ARE CAREGIVERS OF PERSONS WITH END

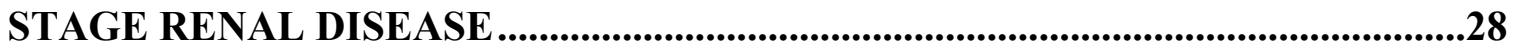

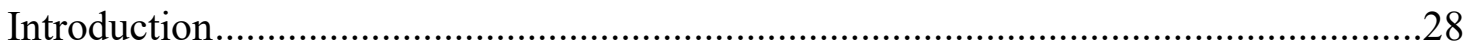

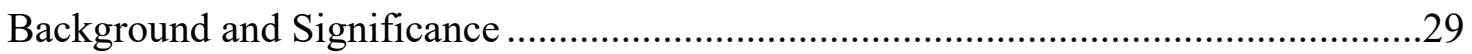

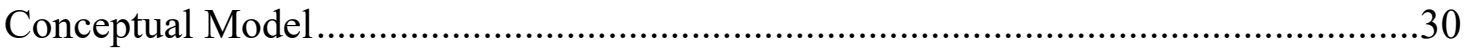

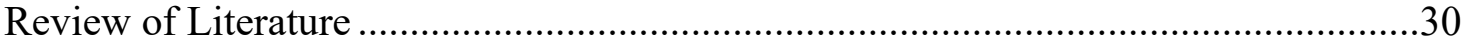

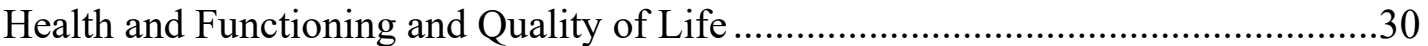

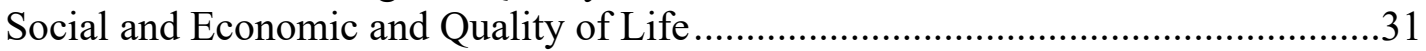

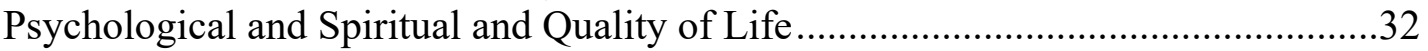

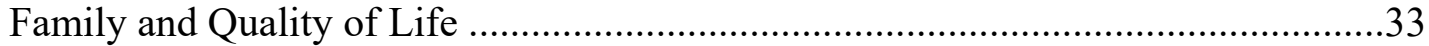

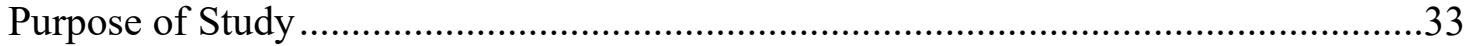

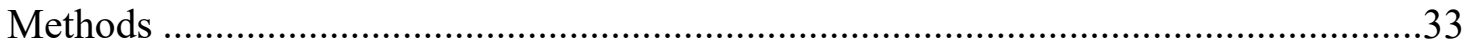

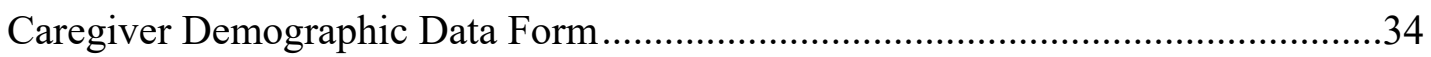

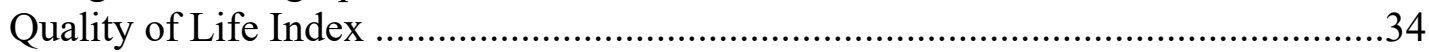

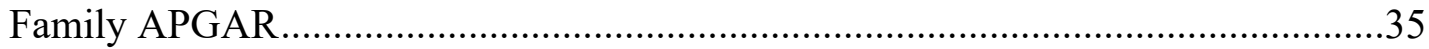

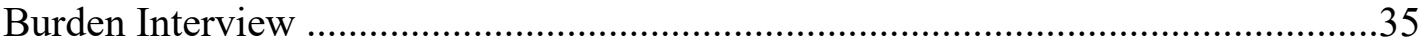

Center for Epidemiologic Studies Depression Scale .......................................... 35

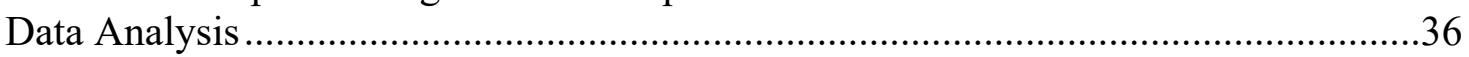

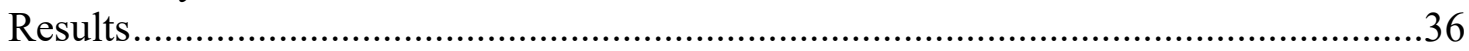

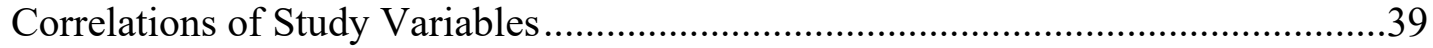

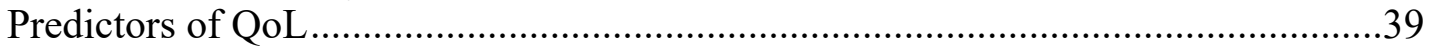

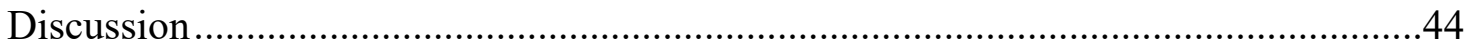

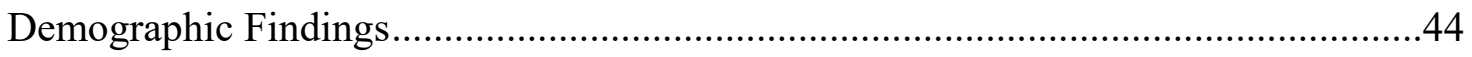

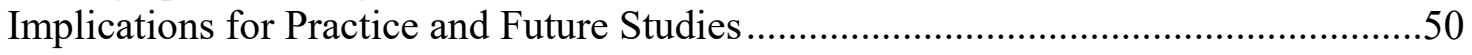

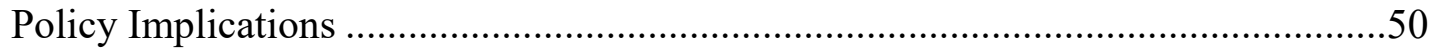

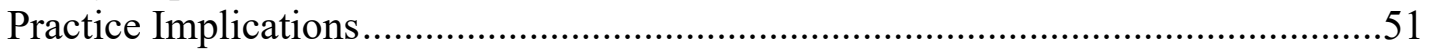

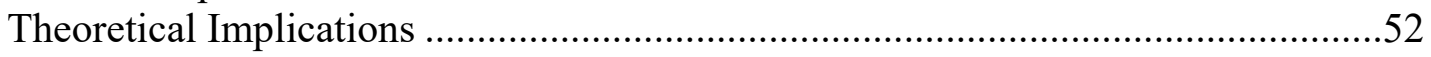

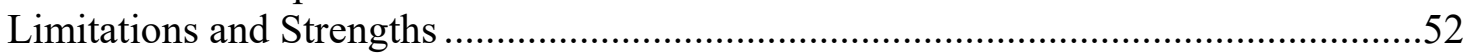

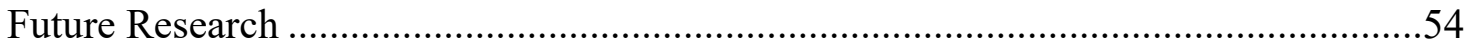

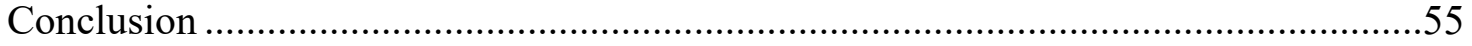

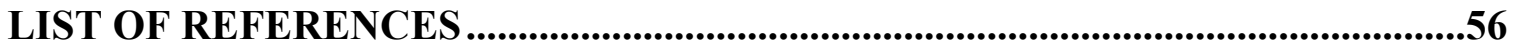

APPENDIX. INSTITUTIONAL REVIEW BOARD APPROVAL LETTER ...........72

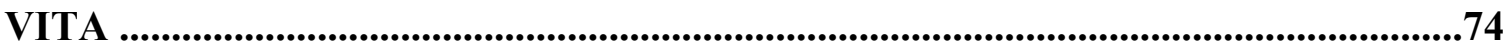




\section{LIST OF TABLES}

Table 2-1. Elements of Ferrans' Conceptual Model for Quality of Life. ......................12

Table 4-1. Description of Demographic Characteristics of Caregivers.........................37

Table 4-2. Means and Ranges of Demographic Characteristics.................................37

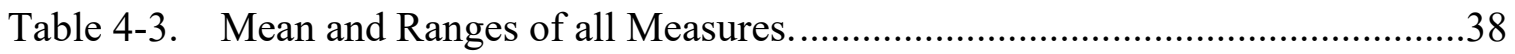

Table 4-4. Correlation Coefficients: Relationship between Quality of Life and Caregiver Demographics. .....................................................................40

Table 4-5. One-way ANOVA of Caregiver Demographic Characteristics by QoL.......40

Table 4-6. Independent Samples t-test of QoL by Residential and Marital Status........41

Table 4-7. Correlations: QoL and Depressive Symptoms, Family Health/Happiness,

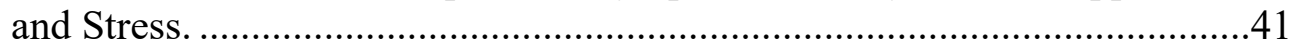

Table 4-8. Dummy Codes of Categorical String Variables. ......................................42

Table 4-9. Predictors of Quality of Life. ...............................................................42

Table 4-10. Predictors of Quality of Life Using Step-type Regression (Backward Elimination). 


\section{LIST OF FIGURES}

Figure 2-1. Ferrans' Conceptual Model for Quality of Life........................................10 


\section{CHAPTER 1. INTRODUCTION}

\section{Background}

Approximately 44 million adults are caregivers who provide nearly 24 hours of unpaid care weekly to persons 50 years of age or more with a chronic illness. These chronic conditions often leave the care recipients incapable of performing many activities of daily living such as managing medications, bathing, and preparing meals (Houser \& Gibson, 2008; National Alliance for Caregiving and AARP Public Policy Institute, 2015).

An estimated 470 billion dollars would be required to pay professional health care providers to deliver the service that caregivers provide annually in the U.S (Reinhard, Feinberg, Choula, \& Houser, 2015). Moreover, caregivers extend their services for approximately five years. Most caregivers $(60 \%)$ are women who are 49 years of age. These caregivers usually care for a spouse or parent (National Alliance for Caregiving and AARP Public Policy Institute, 2015). Thus, women are crucial in sustaining the U.S. health care system.

Caregiving is considered a natural role for women (Houser \& Gibson, 2008). However, caregiving is complicated and often results in psychological, economical, sociological, and physical problems that may have a dynamic impact on the quality of life (QoL) of the caregiver (Houser \& Gibson, 2008; National Alliance for Caregiving and AARP Public Policy Institute, 2015).

End-stage renal disease (ESRD), the last stage of chronic kidney disease, requires renal replacement therapy, such as dialysis or kidney transplant, for survival. Since the introduction of dialysis around 1960, the life expectancy for persons with ESRD has significantly improved (Mailoux \& Burkart, 2015). The incidence of ESRD has increased among people over 45, with the most drastic increase among those over the age of 64 (United States Renal Data System, 2015). Older people with ESRD often have many comorbidities (such as dementia and hypertension) and frail health (Elliott, 2012; Singh, Germain, Cohen, \& Unruh, 2014).

A disproportionate number of individuals with ESRD are African American with incidence and prevalence rates highest among Native Americans, Asian Pacific Islanders, and Whites, respectively (United States Renal Data System, 2015). The leading causes of ESRD in African Americans is diabetes and hypertension (National Kidney Foundation, 2015). Most African Americans receive hemodialysis (United States Renal Data System, 2015), and have low rates of kidney transplantation (Nzerue, Demissachew, \& Tucker, 2002). African Americans who receive hemodialysis, and have both diabetes and hypertension, experience more complications related to these chronic conditions than other racial and ethnic groups who receive the same therapy. Furthermore, hemodialysis in African Americans often results in poorer dialysis outcomes (i.e., clinical parameters such as dialysis adequacy and anemia), than outcomes of Whites, Hispanics, and Asians. Even though African Americans with these problems may experience more 
complications, they have higher survival rates on dialysis than other ethnic groups. Therefore, African Americans may require assistance for extended periods of time. Because the management of ESRD is complex (Mailoux \& Burkart, 2015), individuals may need the help of informal caregivers. Informal caregivers provide unpaid care to family members or friends who are chronically ill and unable to cope with and manage their conditions alone (Gayomali, Sutherland, \& Finkelstein, 2008; National Alliance for Caregiving and AARP Public Policy Institute, 2015). These African American caregivers are usually women who tend to have existing health problems that worsen in the context of providing care (Family Caregiver Alliance: National Center on Caregiving, 2015; Gibbins et al., 2009).-Caregiving is often seen as a natural activity for women, even though the role has the potential to impair caregivers' QoL (Family Caregiver Alliance: National Center on Caregiving, 2015; Houser \& Gibson, 2008). Determining various factors that are associated with overall QoL in African American women who are caregivers may lead to interventions and treatments that address areas that may negatively affect their QoL. Interventions that improve poor QoL or sustain good QoL in caregivers may also improve QoL and health outcomes for care recipients.

Because of the economic, physical, psychological, and social demands of the caregiving, QoL has been an significant area of study among researchers (Lefaiver, Keough, Letizia, \& Lanuza, 2009; Rodrigue \& Baz, 2007). A common concern among researchers is that caregiving can lead to poor health outcomes that are associated with impaired QoL in caregivers (Lim \& Zebrack, 2004; Pressler et al., 2009; RodriguezSanchez et al., 2011). Researchers have found that caregivers provide quality care when they have favorable QoL; thus, assessment of caregivers' QoL may be beneficial to both the caregiver and the care recipient (Belasco, Barbosa, Bettencourt, Diccini, \& Sesso, 2006; Ferrans, Zerwic, Wilbur, \& Larson, 2005; Rees, O'Boyle, \& MacDonagh, 2001). Not only have researchers recognized the importance of measuring QoL, but also have many leading national organizations. Around 1998, the World Health Organization favored measuring QoL and began using the concept as a determinant of health rather than assessing morbidity and mortality rates (World Health Organization, 1998). The Centers for Disease Control and Prevention (2009) stressed the importance of addressing depression and promoting caregiver interventions and QoL by preventing and controlling disease, injury, and disability-a goal that is significant for family caregivers. Further, the Office of Disease Prevention and Health Promotion (2014b) established a goal to assist individuals of all ages to improve their QoL. Within this goal health related quality of life (HRQoL) is viewed as a determinant of health. Health-related QoL differs from overall QoL because it pertains to only physical and psychological domains of the concept; however, this goal has relevance in the current study because the conceptualization of overall QoL includes the domain of HRQoL. A second Office of Disease Prevention and Health Promotion (2014b) goal relevant to the current study is to improve the health, function, and QoL of older persons; this too has relevance for the present study since the average age of persons with ESRD in the U.S. is 64 (United States Renal Data System, 2015). Finally, a third Healthy People 2020 goal that has implications for caregivers is to decrease the proportion of unpaid informal caregivers of older adults who report an unmet need for caregiver support services. 
The assessment of QoL may provide insight into areas of life that African American women value as they provide assistance to their loved ones with ESRD. The nature of and treatment for ESRD is complex and requires demanding physical care, adhering to strict dietary requirements, managing household and financial affairs, dealing with disruptive schedules, and observing care recipients' health decline (National Institute of Diabetes and Digestive and Kidney Diseases, 2014a). Compared to noncaregivers, informal caregivers experience impaired QoL because of poorer mental and physical health (M.H. Bellin et al., 2013; Family Caregiver Alliance: National Center on Caregiving, 2006). Therefore, the QoL of African American women who are caregivers of persons with ESRD may be associated with physical, psychological, social, economic, and familial factors.

\section{Significance of the Problem}

Caregiving has the potential to affect negatively caregivers' QoL. Studies have reported that compared to non-caregivers and care recipients, informal caregivers report the poorest QoL (Çelik, Annagur, Y1lmaz, Demir, \& Kara, 2012; Haley, Roth, Hovater, \& Clay, 2015; Mellon, Northouse, \& Weiss, 2006; Spencer, Goins, Henderson, Wen, \& Goldberg, 2013). Little is known about the QoL of African American women who are caregivers of persons with ESRD who receive hemodialysis. Many studies that have assessed QoL in the context of ESRD in recent years focused on, children with chronic kidney disease (Kilis-Pstrusinska et al., 2013; McKenna et al., 2006) and children with a donor's kidneys (Tsai, Liu, Tsai, \& Chou, 2006). Additionally, researchers have assessed QoL of caregivers of care recipients who use peritoneal dialysis (Fan, Sathick, McKitty, \& Punzalan, 2008) and kidney transplant (Rodrigue et al., 2010). Many investigators from other countries such as Brazil (Belasco et al., 2006), London (Fan et al., 2008), Japan (Shimoyama et al., 2003), Turkey (Çelik et al., 2012), and Thailand (Limpanichkul, 2004) have also examined caregivers' QoL in the context of ESRD. Thus, the importance of assessing caregiver QoL is a worldwide phenomenon.

The lack of a significant number of studies that have assessed QoL in the context of ESRD of caregivers who are African American women is surprising considering the illness disproportionally affects African Americans (United States Renal Data System, 2015). African Americans make up about 15\% of the population (Centers for Disease Control, 2015), but comprise $32 \%$ of the cases of ESRD (United States Renal Data System, 2015). Many studies of African American caregivers in the context of ESRD have examined perceived health status (D. J. Byers, Beard, \& Wicks, 2009) depressive symptoms and health promotion (D.J. Byers, Wicks, \& Beard, 2011; Wicks, Bolden, Mynatt, Rice, \& Acchiardo, 2007), burden (T. T. Harris, Thomas, Wicks, Faulkner, \& Hathaway, 2000; Wicks, Milstead, Hathaway, \& Cetingok, 1998), QoL of caregivers who attended a pre-transplant clinic (Wicks, Milstead, Hathaway, \& Cetingok, 1997), and QoL of caregivers post kidney transplant (Wicks et al., 1998). Though the latter studies examined QoL, caregivers of family members on hemodialysis may significantly differ from caregivers of family members who are awaiting a kidney transplant, or caregivers who have a donor's kidney. All types of renal replacement therapy (i.e., donor's kidney, 
peritoneal dialysis, hemodialysis, continuous ambulatory peritoneal dialysis) come with their individual challenges and advantages (Noshad, Sadreddini, Nezami, Salekzamani, \& Ardalan, 2009). However, individuals who receive hemodialysis experience more difficulty related to renal replacement therapy than those who receive other types of renal replacement therapy.

For this reason, caregivers of care recipients who receive dialysis may have a less favorable QoL than caregivers of persons other types of renal replacement therapy because of the difficulties care recipients face. Moreover, individuals who receive hemodialysis have lower QoL than those who receive peritoneal dialysis (Noshad et al., 2009), CAPD (Makkar, Kumar, Mahajan, \& Khaira, 2015), and kidney transplantation (Tonelli et al., 2011), and this may also affect the caregiver.

In the U.S., people with ESRD start dialysis on average at age 64 (United States Renal Data System, 2015); thus, African American women who are caregivers of people with ESRD face challenges of providing sophisticated care, and may have the responsibility of providing care for an aging or older relative.

African American women who are caregivers may be susceptible to adverse effects associated with caregiving (Powe, Cooper, Kaw, \& Ross, 2013; Zauszniewski, Bekhet, \& Suresky, 2009), because of current disparate health conditions. Compared to other ethnic groups, African American women experience the worst health outcomes (Office of Women's Health, 2012). African American women's general SES is among the lowest of other U.S. ethnic groups, which may negatively affect their QoL. Many African American women work - half of the workforce are African American women, but they often earn low wages (Office of Research on Women's Health, 2014). Socioeconomic factors have been reported to affect negatively the health of African Americans (Byrd \& Clayton, 2001). Ethnic minorities with overall low SES experience high psychological stress, racial discrimination, and often do not receive preventive care (American Psychological Association, 2016a).

Overall, African Americans experience more physical and mental health disparities, morbidity, and mortality than any other ethnic group in the U.S. However, African American women have more adverse outcomes related to health disparities than African American men (Office of Research on Women's Health, 2014; Office of Women's Health, 2012). Examples of how African American women neglect their health include failure to care for chronic illnesses, or receive of care when a disease is irreversible or difficult to treat (i.e., later stage breast cancer) (National Cancer Institute, 2008; Office of Women's Health, 2012).

Psychological health in African Americans has been a complicated issue in research. This particular domain may be problematic in the assessment of QoL. Many standard measures of QoL include assessment of psychological domains such as the Short Health Survey Form (36SF-36) (Ware \& Sherbourne, 1992) and The World Health Organization Quality of Life-BREF(WHOQOL-BREF) (World Health Organization, 2012). 
African Americans' response to stress and depression is misunderstood and is often under-diagnosed or undetected (Jones \& Shorter-Gooden, 2003; Woods-Giscombe, 2010). Many studies highlight poor mental health as a major contributor to poor QoL in caregivers; however, African American caregivers do not frequently report depressive symptoms as it is often viewed as a weakness. African American caregivers often deny stress because caregiving is an expected role embedded in tradition and culture. A struggle is often "normalized" as strength — a paradox that may silently exacerbate and deteriorate the mental health of African Americans (Beauboeuf-Lafontant, 2008; Black \& Peacock, 2011; Sohail, Bailey, \& Richie, 2014; Woods-Giscombe, 2010). African Americans frequently suffer from chronic stress, allostatic load, and may exhibit nontraditional signs and symptoms of depression and stress such as hypertension, obesity, and poor physical health such as heart disease and chest pain (Deuster, Kim-Dorner, Remaley, \& Poth, 2011; Jackson, Knight, \& Rafferty, 2010; Sohail et al., 2014; Sok, 2010). Worry, stress, energy, mood, and weight were reported to worsen for some African American women caregivers of persons with ESRD after they started the role (D.J. Byers et al., 2011). African American women with repeated reports of somatic symptoms, even in the absence of clinically significant scores on depression screening instruments, may be depressed as African Americans tend to report more somatic, rather than affective symptoms of the disorder (Bailey, Blackmon, \& Stevens, 2009). These issues may be associated with an overall higher morbidity rate among African Americans, which could negatively affect overall QoL.

To add to the paradoxical psychological health that may misconstrue QoL that is reported in African Americans, the inconsistent conceptualizations of QoL also creates problems with assessment of QoL (Anderson \& Burckhardt, 1999; DeVon \& Ferrans, 2003; Ferrans, 1996; Prutkin \& Feinstein, 2002). According to Ferrans' Conceptual Model for Quality of Life, people value different things; therefore, differences in QoL may exist among caregivers based on their uniqueness (Ferrans, 1996). What are the different factors that are important to some family caregivers of patients with ESRD that may not be important to others? What are the factors that significantly impact the QoL of caregivers of patients with ESRD? The goal of this study was to describe predictors of QoL in African American women who care for persons with ESRD.

Thus, this study will describe factors that are associated with QoL in caregivers of persons with ESRD using Ferrans' Conceptual Model for Quality of Life, and the predictors of QoL in African American women who are caregivers of person with ESRD using Ferrans' Conceptual Model for Quality of Life (Ferrans, 1996) . 


\section{CHAPTER 2. QUALITY OF LIFE OF AFRICAN AMERICAN WOMEN CAREGIVERS: A LITERATURE REVIEW}

The life expectancy for people with ESRD has significantly improved since the introduction of dialysis around 1960 (Mailoux \& Burkart, 2015). However, people who receive dialysis experience many complications and poor QoL (Sathvik, Parthasarathi, Narahari, \& Gurudev, 2008). Hemodialysis results in dependence on others, loss of leisure time, and disruption in relationships with friends and family. Thus, individuals who receive hemodialysis experience many issues that may negatively affect their QoL. Healthy People 2020 recognized chronic kidney disease and ESRD as significant public health problems and major sources of poor QoL and suffering for those with the condition. For this reason, Healthy People 2020 established a goal to reduce the incidence of chronic kidney disease and its complications, disability, death and economic cost (Office of Disease Prevention and Health Promotion, 2014a).

A disproportionate number of individuals with ESRD are African American with the highest incidence and prevalence rates of Native Americans, Asian Pacific Islanders, and Whites, respectively (United States Renal Data System, 2015). The two leading causes of high prevalence rates of ESRD in African Americans are diabetes and hypertension (National Kidney Foundation, 2015). African Americans have the highest hemodialysis survival rate than other ethnic groups. Nonetheless, African Americans experience many complications associated with hemodialysis when they also have diabetes, and hypertension. Because the management of ESRD is complicated, individuals may require assistance from formal caregivers (Mailoux \& Burkart, 2015). The complexity of care that is required may gravely affect the QoL of caregivers (Wilson-Genderson, Pruchno, \& Cartwright, 2009).

Evaluation of caregivers' QoL has become a new priority because researchers have recognized that the quality of care that is provided to care recipients is associated with the caregivers' QoL (Belasco et al., 2006; Ferrans et al., 2005; Rees et al., 2001). Many leading national organizations such as The World Health Organization (2012), Office of Disease Prevention and Health Promotion (2014b), and the Centers for Disease Control and Prevention (2009) have emphasized the importance of measuring QoL in all individuals.

Discovery of factors that affect the QoL of African American women who are caregivers of persons with ESRD who receive hemodialysis may lead to better recognition of factors that improve or impair QoL. Tailored intervention development and appropriate resource referrals may also benefit the caregivers when QoL is assessed. Furthermore, assessment of QoL is preventive and may help reduce adverse outcomes, or sustain positive outcomes of related to caregiving. Health care providers (HCPs) can potentially monitor for changes in an individual's QoL when they have knowledge of a patient's QoL. Health care providers can tailor care based on a patient's preference. For example, if the family is an important factor that affects a caregiver's QoL, and is rated as 
unsatisfactory, HCP may know that the caregiver needs resources to improve satisfaction. Otherwise, the caregivers' QoL may decline.

It is important that researchers determine the factors that affect the QoL of African American women who are caregivers to develop appropriate interventions. Few studies have examined QoL among African American women in the context of ESRD (Wicks et al., 1997, 1998). Therefore, this review of literature will include a synthesis of studies that explore the QoL of African American caregivers' of care recipients with any chronic illness. Findings from these studies may provide insight into factors that may affect the QoL of African American women who are caregivers of persons with ESRD. Ultimately, the results from this review of literature will guide a study that will describe the predictors of QoL of African American women who are caregivers of persons with ESRD.

A conceptual framework - Ferrans' Conceptual Model for Quality (1996) -guided this review of literature. This model was chosen because it informs the research aims of the planned study that will describe factors that predict QoL in African American women who are caregivers of persons with ESRD. There are no known existing theories regarding factors that are associated with QoL among African American women who are caregivers. Furthermore, there are inconsistent definitions and measures of QoL in the literature, which makes it difficult to determine the specific factors that are associated with and individuals' QoL. Understanding the domains is critical for the assessment and measurement of individuals' QoL. A succinct explanation of the significance of the problem is presented followed by a brief description of the model; relevant study variables included in the model are also shown. Next, the methods used to conduct the review of literature are described followed by a discussion of research that examines caregiver QoL in general followed by a synthesis of research that looks at caregivers' QoL specifically in the context of ESRD.

\section{Significance of the Problem}

Women in the U.S. are the primary providers of support to family members with chronic health care needs, such as ESRD (Family Caregiver Alliance: National Center on Caregiving, 2015). Moreover, women who are caregivers are usually older and may have preexisting health problems that worsen in the context of caregiving (Gibbins et al., 2009). For this reason, caregiving is a task that may worsen the health and QoL of African American women. African Americans comprise 15\% of the U.S. population and are mainly concentrated in the southeastern region of the U.S. Even though African Americans make up a small portion of the U.S. population, this group experiences greater disparities in health, higher morbidity, and higher mortality rates than other ethnic groups in the U.S. (Centers for Disease Control, 2015).

Assisting a person who requires dialysis for ESRD may cause significant changes that affect caregivers' health and QoL (Gill et al., 2011). In general, much of the literature about African American women caregivers has focused on those who provide 
care for grandchildren (del Bene, 2010), elderly persons with dementia (Belle et al., 2006; Moon \& Dilworth-Anderson, 2015), stroke (Haley et al., 2015) or persons with cancer (Powe et al., 2013). The focus of these studies are usually outcomes such as stress (Siefert, Williams, Dowd, Chappel-Aiken, \& McCorkle, 2008) and positive rewards of caregiving (Hargrave, 2006; Roff et al., 2004).

Quality of life is a subjective and comprehensive concept that reflects many facets of one's life. Thus, it is an appropriate measure to determine how the task of caregiving affects caregivers' lives. Assessments of QoL may be more comprehensive and insightful than assessments of frequently reported caregiving outcomes, such as stress, self-health perception, anxiety, and depression because the assessment of QoL is from the individual's perspective (Ferrans, 1996).

The conceptual definition of QoL validates it as an important outcome measure. Quality of life quantifies people's perception of their life, assesses areas of their life that are characterized as satisfactory or that require improvement, and provides an overall indication and rank of all aspects of life that people value (Ferrans, 2007). Assessment of QoL is a holistic practice which may help avoid disease and disability for caregivers and also prevent potential problems for care recipients (Canam \& Acorn, 1999). It is necessary to understand the underlying disease and factors that affect the way in which caregivers cope with relatives with the disease to understand the QoL of African American women caregivers of persons with ESRD.

This section addresses physiology and implications of the physiological changes that occur when individuals have ESRD. Caregivers of persons with ESRD may have impaired QoL such as that of caregivers who assist persons with other chronic illnesses (T.T. Harris, 2003; Mellon et al., 2006). Researchers have reported that individuals who receive hemodialysis experience poorer QoL than individuals with diabetes, heart failure, and chronic lung disease; thus, the caregiver may also experience poor QoL (Anees, Hameed, Mumtaz, Ibrahim, \& Saeed Khan, 2011). The nature of and treatment for ESRD is critical because it includes demanding physical care, managing household and financial affairs, dealing with disruptive schedules, and observing care recipients' worsening condition. Dialysis is a complicated therapy that is initiated when kidneys fail. Healthy kidneys are responsible for homeostasis. The kidneys regulate volume by the production and elimination of urine, electrolyte concentration, acid-base balance, elimination of waste, detoxification of blood, and production of hormones responsible for erythropoiesis, blood pressure regulation, and bone growth (National Institute of Diabetes and Digestive and Kidney Diseases, 2014a). When an individual has ESRD, the kidneys no longer perform these vital functions and renal replacement therapy is required for the individual with ESRD to survive. Anemia, extreme pruritus, and insomnia are common. Patients who start hemodialysis are expected to adhere to a strict schedule for dialysis treatments three times per week.

Thus, activities and work usually drastically change for affected individuals. These changes can be tough for families. Consequently, many affected individuals become exhausted and depressed after they start dialysis. The strict dialysis schedule, 
fatigue, and depression experienced by care recipients on dialysis may create dependence on others. The other people are often family members who help the care recipient manage their chronic condition and life (Axelsson, Randers, Jacobson, \& Klang, 2012; The National Kidney and Urologic Diseases Information Clearinghouse (NKUDIC) (2006).

Individuals with ESRD also have to adhere to strict dietary guidelines. Since the kidneys no longer function properly, people with ESRD must limit fluid intake, monitor potassium, phosphorus, and food with sodium. Arrhythmias may occur if the care recipient consumes excessive amounts of potassium, which increases the risk of heart attack. When phosphorus is consumed in excess, calcium depletes from bones and leads to bone diseases; excess fluid can result in congestive heart failure. People who receive dialysis must also supplement and consume adequate protein since protein, and other essential nutrients are depleted after dialysis treatments. Additionally nutritional demands are paramount because many foods that are restricted contain vital nutrients that persons who receive dialysis need (National Institute of Diabetes and Digestive and Kidney Diseases, 2014b).

Other than assisting with activities of daily living such as food preparation and shopping, caregivers of persons with ESRD also often have the responsibility of advocating for the recipient, transporting the recipient to doctor's appointments and dialysis centers, and providing emotional support when needed (Beanlands et al., 2005; Rodrigue et al., 2010). These varied and continuous illness-focused obligations combined with other familial and employment obligations cause significant problems for caregivers. Caregiving places limitations on social activities, contributes to spousal relationship strain, sleep problems, exhaustion, and a loss of privacy (Beanlands et al., 2005; Otis-Green \& Juarez, 2012; Rodrigue et al., 2010). The many physical, social, and emotional challenges experienced by people with the disease may indirectly affect their caregivers (Wicks et al., 2007), but caregivers' needs are often overlooked in the presence of the care recipients many issues.

\section{Conceptual Model}

Ferrans' Conceptual Model for Quality of Life (Ferrans, 1996) was the model used in this study. Quality of life has been conceptualized and operationalized inconsistently in the literature. Various approaches that are used to measure the concept makes the comparison of studies difficult and creates challenges for the development of interventions that may address areas of concern that affect QoL (DeVon \& Ferrans, 2003; Ferrans, 1996). Conceptual inconsistency related to QoL can yield significant differences in research and clinical outcomes. Ferrans' definition of QoL suggests that a person is the ultimate judge of his or her life as people value different things; therefore, differences in QoL can exist among people (Ferrans, 1996). Ferrans' Conceptual Model for Quality of Life consists of four domains: health and functioning, psychological and spiritual, social and economic, and family domains (Figure 2-1). Different factors that were derived from the literature and that may be significant to African American women who are caregivers 


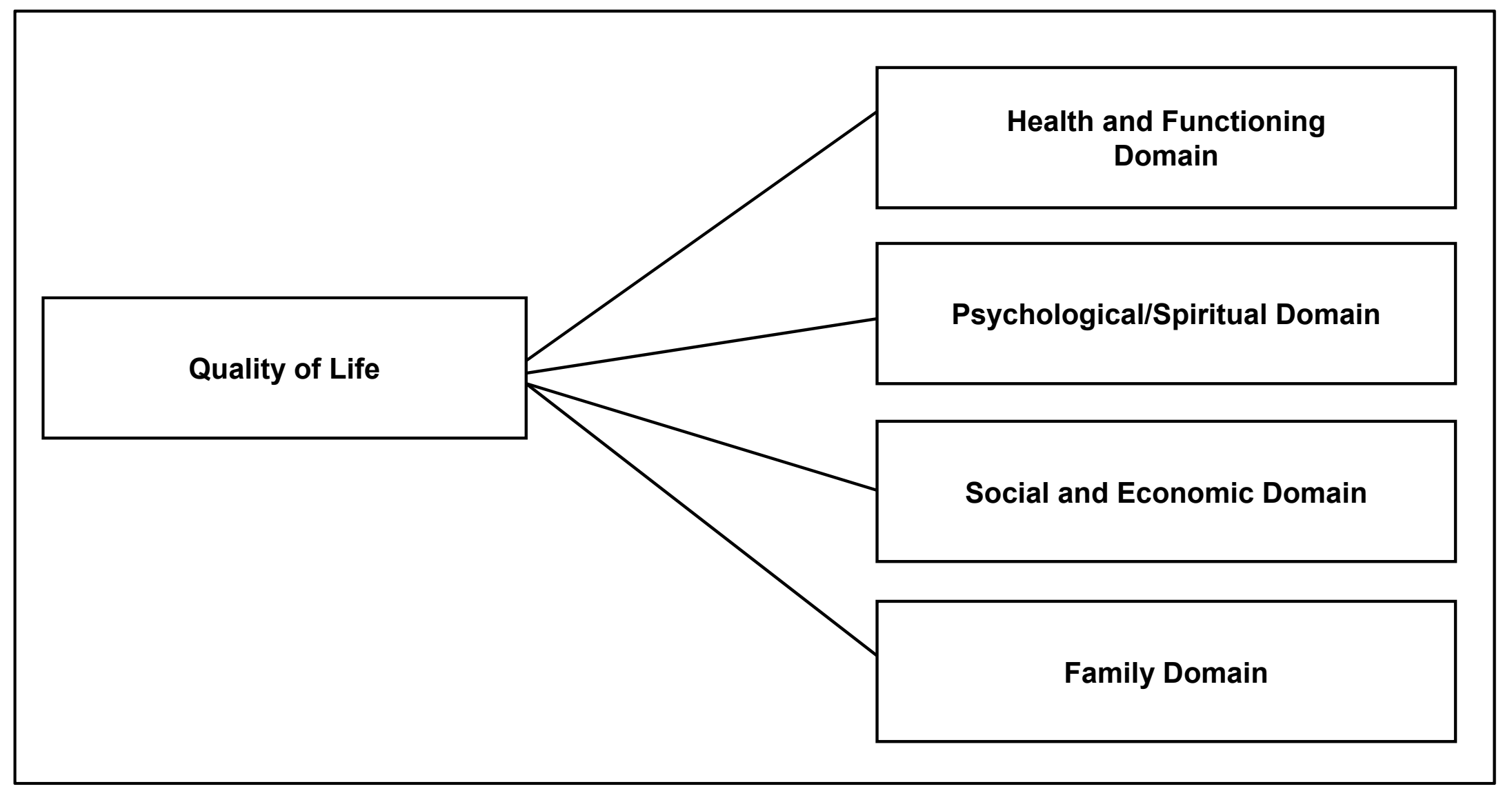

Figure 2-1. Ferrans' Conceptual Model for Quality of Life.

Reprinted with permission: Ferrans, C.E. (1996). Development of a conceptual model of quality of life. Scholarly Inquiry for Nursing Practice, 10(3), 293-304. 
of persons with ESRD will be explored. Table 2-1 provides a list of elements within each domain.

\section{Methods}

Of the 58 studies found, 19 were used in this review based on study applicability to African Americans who care for persons with ESRD. We excluded studies for the following reasons: 1) duplicates, 2) outcomes did not focus on caregivers' QoL, 3) caregivers were only male, or 4) the study did not address race, ethnicity, or culture. We included other ethnic groups and other chronic illnesses in the review because of the paucity of research about QoL among African American caregivers of persons with ESRD. Also, six studies that used (Ferrans \& Powers, 1985) Quality of Life Index ( based on Ferrans' QoL model) were also examined. Inclusion criteria were as follows: Peerreviewed studies that have examined QoL in caregivers from any ethnic minority group, provide care for a person with any chronic illness, and written in English and published between January 2005 and December 2015. CINAHL C, PubMedC), and Psychoinfo (C) were used to identify studies. The following terms guided the selection of articles: "African-American," "ethnic minority", minority, caregiver, and "quality of life," endstage renal disease, dialysis, "Quality of Life Index," and "QLI." Most of the selected studies included information about race, culture, or ethnicity in the title, abstract, or keywords.

We categorized the results from all studies into the corresponding domains of Ferrans' Conceptual Model for Quality of Life (QLI) and systematically reviewed and compared the studies. Several of the studies that we found included information that was relevant in more than one domain of Ferrans' Conceptual Model for Quality of Life. The interrelation that we found among the studies validated the multidimensionality of QoL in the caregiving literature. For example, stress contributes to physical and psychological responses that can affect QoL.

\section{Health and Functioning and Quality of Life}

Stress. African American women may not experience high levels of stress as a result of caregiving. Findings from several cross-sectional studies found that African American women report little to no stress when they provide care for persons post-stroke (Clay et al., 2013), with cancer (Powe et al., 2013), who are older adults (Roth, Perkins, Wadley, Temple, \& Haley, 2009), and with serious mental illnesses (Zauszniewski et al., 2009). One longitudinal study of African American women caregivers of children with asthma reported that caregivers experienced low levels of stress that improved from baseline to 6 and 12 months (M. H. Bellin et al., 2015).

Furthermore, results from many cross-sectional studies are similar and report an inverse relationship between QoL and stress. For example, with caregivers of children 
Table 2-1. Elements of Ferrans' Conceptual Model for Quality of Life.

\begin{tabular}{|c|c|c|c|}
\hline $\begin{array}{c}\text { Health and Functioning } \\
\text { Domain }\end{array}$ & $\begin{array}{l}\text { Psychological and } \\
\text { Spiritual Domain }\end{array}$ & $\begin{array}{c}\text { Social and Economic } \\
\text { Domain }\end{array}$ & Family Domain \\
\hline Usefulness to others & Satisfaction with life & Standard of living & Family happiness \\
\hline Physical independence & Happiness in general & Financial independence & Children \\
\hline $\begin{array}{l}\text { Ability to meet family } \\
\text { responsibilities }\end{array}$ & & $\begin{array}{l}\text { Home (apartment, } \\
\text { house) }\end{array}$ & $\begin{array}{l}\text { Relationship with } \\
\text { spouse }\end{array}$ \\
\hline Own health & $\begin{array}{l}\text { Achievement of personal } \\
\text { goals }\end{array}$ & Neighborhood & Family health \\
\hline Pain & Peace of mind & Job & \\
\hline Energy (fatigue) & Personal appearance & Friends & \\
\hline Stress/worries & & $\begin{array}{l}\text { Emotional support from } \\
\text { others }\end{array}$ & \\
\hline Control over life & & Education & \\
\hline Leisure time activities & & & \\
\hline $\begin{array}{l}\text { Potential for a happy old } \\
\text { age/retirement }\end{array}$ & & & \\
\hline $\begin{array}{l}\text { Ability to travel on } \\
\text { vacations }\end{array}$ & & & \\
\hline Potential for long life & & & \\
\hline Sex life & & & \\
\hline Health care & & & \\
\hline
\end{tabular}


with asthma, (M.H. Bellin et al., 2013) adults with heart failure (Saunders, 2009), poststroke care recipients (Clay et al., 2013), children with chronic lung disease (Feeley et al., 2014), dementia care recipients (Kaufman, Kosberg, Leeper, \& Tang, 2010), and care recipients of elderly persons (Meecharoen, Sirapo-ngam, Monkong, Oratai, \& Laurel, 2013; Roth et al., 2009), and care recipients with cancer (Powe et al., 2013) experienced poor QoL as their stress increased. Conversely, a longitudinal study of African American women caregivers of children with asthma showed improvements in their QoL and stress levels from baseline to 6 months, and 12 months. However, the difference between the longitudinal and cross-sectional study was an intervention. The longitudinal study implemented a behavioral and educational intervention that may explain the improvement of QoL and low levels stress over time.

\section{Usefulness to Others, Fatigue, Own Health}

Studies consistently show that caregivers from ethnic minority groups who are overwhelmed and unprepared for their role experience poor QoL. Collins and Swartz (2011) reported that many caregivers feel unprepared because of no formal education about caregiving. For instance, caregivers of adult with a donor's lung (Lefaiver et al., 2009), or children with a chronic lung disorder (Feeley et al., 2014) were overwhelmed with caregiving responsibilities. This feeling of being overwhelmed may affect caregivers' usefulness to others.

Moreover, caregivers report exhaustion related to caregiving activities. One qualitative study found that ethnic minority caregivers of persons with a donor's lung experienced fatigue from their role (Lefaiver et al., 2009). Many caregivers experience insomnia; thus, exhaustion may result from poor quality sleep (Feeley et al., 2014; Powe et al., 2013). Inadequate sleep was shown to impair QoL of African American women who were caregivers of breast cancer survivors (Powe et al., 2013). Fatigue and insomnia may have a psychological etiology. Physical and psychological factors often interrelate. For instance, caregivers who suffer from depression have more sleep problem and chronic illnesses (Feeley et al., 2014). Caregivers may experience a myriad of symptoms because they often neglect their health care needs.

Results from cross-sectional studies that compare African American and White caregivers of heart failure care recipients reported that the caregivers with health problems reported poor QoL (Saunders, 2009). Other studies reported that African American caregivers with poor physical health experienced poorer QoL than Whites (Feeley et al., 2014; Zauszniewski et al., 2009). One longitudinal study compared African American and White caregivers of persons post-stroke over a period of three years (Haley et al., 2015). These researchers found that caregivers' QoL declined over a period of three years when they experienced many physical health problems (Haley et al., 2015). 


\section{Control Over Own Life, Leisure Time Activities}

Research findings validate caregivers' experiences with loss of control over life and lack of time for self-care (Saunders, 2009). Many caregivers devote time to the care recipient and consistently neglect themselves because of overwhelming caregiving responsibilities (Powe et al., 2013). Results from cross-sectional studies report that interruptions in caregivers' schedule and long durations of care may negatively impact caregivers' QoL, and worsen their physical health (Powe et al., 2013; Saunders, 2009).

\section{Summary}

In summary, we examined ten studies that addressed the association between QoL and health and functioning as listed in Ferrans' Conceptual Model for QoL. African American women who are caregivers of persons with ESRD may experience many health and functioning problems that affect their QoL such as stress, fatigue, loss of leisure time and control over their life. Many caregivers experience a decline in health as a result of these factors. Caregivers' functioning, health, and QoL may also decline when they experience health problems compounded by the time-consuming demands of caregiving. African American women who are caregivers experience low levels of stress and poor to average QoL. Though African American women experience disparate health conditions (Office of Women's Health, 2012), caregiving does not seem to affect their QoL (Clay et al., 2013).

\section{Psychological and Spiritual and Quality of Life}

\section{Happiness in General}

No studies examined or measured "happiness," but many studies commonly measured depressive symptoms among caregivers. Some research findings suggest that caregivers' QoL declines as they experience more depression (Saunders, 2009). Researchers have also found that African Americans have better psychological outcomes (i.e., low depressive symptoms) than Whites (Clay et al., 2013). When African American caregivers assisted persons post-stroke, they experienced better mental-health related QoL and less emotional and mental strain than Whites who cared for persons post-stroke (Clay et al., 2013), and elderly care recipients (Roth et al., 2009).

Psychological outcomes may not change over time as caregivers serve in the role. For instance, the impact of stroke on caregivers' QoL and depression was examined over a three-year period (Haley et al., 2015). African Americans experienced less depression than Whites even though their care recipients experienced greater impairments in health. Researchers speculate that African Americans are resilient; therefore, they experience less depression in response to caregiving (Clay et al., 2013; Haley et al., 2015; Roth et al., 2009). 
The role of a caregiver may provide reward and satisfaction for African Americans. Caregiving is seen as a reward because caregivers can establish closer relationships with the care recipient. Caregiving also allows African Americans the ability to express reciprocity in their relationship. Caregiving, often seen as a unique opportunity, helps some individuals discover new meaning in life and helps personal growth (Teschendorf et al., 2007).

\section{Satisfaction with Self, Life, and Faith in God}

One cross-sectional study revealed that Blacks who were caregivers of persons with Alzheimer's' disease experienced better spiritual well-being than Whites (Spurlock, 2005). Findings of a longitudinal study conducted over a two-month period examined spirituality/religion in ethnic minority caregivers of persons with cancer. This study reported that caregivers who had poor QoL engaged in more spiritual activities. However, high QoL was positively associated with caregivers who had a religious affiliation (Leow, Chan, \& Chan, 2014). Two other qualitative studies, examined the religion/spirituality and QoL of African American women who were caregivers or elderly persons (Pharr, Frances, Terry, \& Clark, 2014) and breast cancer survivors (Sterba et al., 2014). The common theme reported among these studies was "caregiving is like a ministry." or a "calling" that served as a form of spiritual expression. Even though caregiving is a difficult task, the role strengthened caregivers' relationship and faith in God. The notion that "God is in control," and "would not put anything on me that I could not bear," was a common theme between both studies (Pharr et al., 2014; Sterba et al., 2014). Thus, caregivers reported positive thoughts about their role and felt their role was a way to "give back" and serve God. Furthermore, self-esteem also affects QoL. A crosssectional study of caregivers of individuals with heart failure reported that caregivers who experience high levels of self-esteem experience high QoL (Saunders, 2009).

On the one hand, caregiving is associated with negative outcomes, and on the other hand it has been associated with positive outcomes. In fact, about $83 \%$ of caregivers report positive experiences from caregiving. Caregivers experience a sense of satisfaction when the care recipient benefits or improves from their care. When caregivers experience positive benefits of care, they experience less depression (American Psychological Association, 2016b). Past research has shown that African American s, in particular, experience more reward in their role than White caregivers (Picot, Debanne, Namazi, \& Wykle, 1997). Self-efficacy has potential to affect positively aspects of caregiving (e.g., finding meaning in caregiving), and is negatively related to psychological symptoms (e.g., depression) (Semiatin \& O’Connor, 2012)

\section{Summary}

In summary, we examined nine studies that assessed the association between QoL

and psychological and spiritual factors as listed in Ferrans' Conceptual Model for Quality of Life among African American women who are caregivers of persons post-stroke (Clay 
et al., 2013); children with chronic lung disease (Feeley et al., 2014); middle-aged adults and elderly persons (Hebert, Weinstein, Martire, \& Schulz, 2006; Roth et al., 2009); lung transplant care recipients (Lefaiver et al., 2009) ; and seriously mentally ill adults (Zauszniewski et al., 2009). Psychological and spiritual factors may affect the QoL in African American women who are caregivers. Religion and spirituality are significant factors in the lives of many African Americans and a source of major support for many African American women Wednesday (Holt et al., 2009). Nonetheless, African American women who are caregivers do not seem to experience the depression that is commonly associated with caregiving in other populations. Additionally, African Americans often report that they felt obligated to care for care recipients based on their kinship ties (Pharr et al., 2014; Sterba et al., 2014). These findings imply a dissonance within caregiving with African Americans. Do these African Americans feel forced to care? Do they feel that it is a calling if they do it out of obligation?

\section{Social and Economic and Quality of Life}

\section{Job/Employment, Education, Financial Independence}

Different study designs report dissimilarities in the association of QoL and SES. Findings from correlational studies show a significant inverse relationship between SES (i.e., education, employment, and income) and QoL in African American woman and other ethnic minority caregivers. For example, African American woman with more education (M.H. Bellin et al., 2013), more income (Modi, Guilfoyle, \& Zeller, 2009; Saunders, 2009), and who were employed (Mellon et al., 2006) had impaired QoL. These caregivers provided care for their children with severe asthma, (M.H. Bellin et al., 2013), children who were obese (Modi et al., 2009), and adults with cancer (Mellon et al., 2006; Saunders, 2009). In contrast, one longitudinal study of African American woman who provided care to their child with asthma reported evidence that employment income, education, and social support did not affect QoL from baseline to 6 and 12 months (M. H. Bellin et al., 2015). As a matter of fact, QoL improved over time for caregivers in this study. The latter study was a randomized control study that used behavioral and educational arms; thus, the interventions may be responsible for the improvements in QoL.

\section{Emotional Support from Others, Friends}

Social support is protective of negative impact of caregiving on ethnic minorities. Several cross-sectional studies revealed that ethnic minority caregivers of person with dementia (Kaufman et al., 2010) and cancer (Meecharoen et al., 2013; Mellon et al., 2006) experienced favorable QoL when they, received social support from family and friends. On the other hand, White caregivers reported poor QoL when they received more social support (Clay et al., 2013). Caregivers who have adequate support may have better QoL. Social support may buffer the adverse effects of caregiving on QoL. For example, 
caregivers of children with chronic kidney disease reported favorable QoL when they received social support (Wiedebusch et al., 2010).

\section{Summary}

In summary, we examined eight studies that assessed the association between QoL and social and economic factors as listed in Ferrans' Conceptual Model for QoL (M.H. Bellin et al., 2013; M. H. Bellin et al., 2015; Clay et al., 2013; Kaufman et al., 2010; Meecharoen et al., 2013; Mellon et al., 2006; Modi et al., 2009; Saunders, 2009). Caregivers are often employed while taking care of a sick relative. Caregivers who have the responsibilities of work, and the obligations to provide care may experience adverse outcomes. Caregivers who work may suffer from poor QoL because of the challenging demands of caregiving and providing income for the home (Teschendorf et al., 2007). To add, women may have more financial difficulty than men when they provide care for a family member with a chronic illness. Women who are caregivers work twice as much as men (Robison, Fortinsky, Kleppinger, Shugrue, \& Porter, 2009).

\section{Family and Quality of Life}

Three cross-sectional studies revealed that QoL was higher when ethnic minority caregivers were satisfied with family functioning while caring for persons with a donor lung (Lefaiver et al., 2009) and cancer (Meecharoen et al., 2013; Mellon et al., 2006). In a cross-sectional study of White caregivers of persons with heart failure, Saunders (2009) found that minimal family support was associated with high QoL. This finding differs from caregivers from ethnic minority groups who report high QoL when they are satisfied with their family functioning (Lefaiver et al., 2009; Meecharoen et al., 2013).

In summary, we examined four studies that assess the relationship between QoL and family as listed in Ferrans' Conceptual Model for Quality of Life (Lefaiver et al., 2009; Meecharoen et al., 2013; Mellon et al., 2006; Saunders, 2009). The family is a major source of support for people with chronic illness (Bamm \& Rosenbaum, 2008). Many African Americans are more likely to live with the care recipient and feel obligated to care for them (Roth et al., 2009; Scharlach et al., 2006). Evidence from this review stresses the importance of assessing one's family functioning. Dissatisfaction with family functioning may ultimately affect the quality of care that caregivers provide (RodriguezSanchez et al., 2011). Family functioning may change and requires reassignment of roles when a family member has a chronic illness. Persons in families with healthy functioning experience a better state of physical and mental health. Caregivers in families with healthy functioning are satisfied with family support, time spent with family, decisionmaking, and affection (Sanchez et al., 2011. 


\section{Discussion}

The purpose of this review of literature was to synthesize studies that examined factors that may affect the QoL of African American woman who are caregivers of persons with chronic illnesses. Although few of these studies focused on caregiver QoL in the context of ESRD, findings from this review provided insight into factors that may affect the QoL of African American woman who are caregivers of persons with ESRD. The results from this review of literature will guide a study that will describe the predictors of QoL of African American woman who are caregivers of persons with ESRD.

We used Ferrans' Conceptual Model for QoL as a roadmap for this review of literature. Little impairment in the domain of health and functioning was observed in African American women who are caregivers. One of the most frequent negative outcomes found in the caregiver literature is stress; however, African American women who are caregivers report little to no stress. Fatigue, uncertainty about the role, leisure time, health problems, and ability to help others seemed to affect the QoL in African American women negatively and substantially in the health and functioning domain. We saw no impairment in the psychological and spiritual domain that would affect the QoL for caregivers who are African American women. These women had better psychological health than other ethnic groups and found reward and strength in caregiving, even when the care recipient had significant needs. Findings suggest that the social and economic domain was the most impactful. Impaired QoL was affected most when African American women who were caregivers were highly educated, employed, or receive high wages. Social support was a positive factor and associated with improved QoL for African American women who provided chronically ill persons. Finally, in the family domain caregivers who were satisfied with family support experienced high QoL.

Not only do African American care recipients with chronic illnesses heavily rely upon relatives who are caregivers, but also they often rely upon others such as friends and neighbors. This heavy reliance is implied from evidence in the health and functioning domain in which African Americans helped others but experienced poor QoL from fatigue and exhaustion, and self-neglect. Further, work obligations may interfere with African American women caregiving obligations and impair QoL and may explain the reason caregivers who are employed, educated and have high income experienced poor QoL.

\section{Implications for Future Research}

The findings from this review of literature will be used to design a quantitative study of secondary data to determine the predictors of QoL of African American women who are caregivers of persons with ESRD. Because there is little research available regarding African American women in the context of ESRD, this review was critical to identify certain factors that could affect QoL in the population of interest. We identified 
many factors that helped fill gaps in knowledge and that will guide the design of the planned study.

A future study could employ a mixed methods approach to help researchers understand African American women caregiving experience. Interviews could clarify participants' survey responses to validate findings from quantitative measures. A mixed methods study could help researchers better understand factors that may affect caregivers' QoL which may help enhance the credibility of the results. Researchers may gain a better understanding of a concept such as QoL using a mixed methods study because the concept is subjective. Measuring a subjective concept without obtaining respondents' explanation may also affect the credibility of the results and development of needed and meaningful interventions.

\section{Conclusion}

This review of literature includes many factors that can affect the QoL of African American women who provide care to persons with chronic illness. The QoL of African American women may diminish when faced with competing demands of work and caregiving. In contrast, African American women's psychological health, satisfaction with social support, family health, and spiritual strength may buffer the adverse effects of caregiving. More investigation into the QoL of African American women who are caregivers is necessary since the role and tasks of supporting chronically ill individuals could negatively affect caregiver health and wellbeing over time. With this knowledge, researchers and clinicians may better understand the needs of these caregivers and develop appropriate interventions and referral of resources. Caregivers may feel supported when their needs are assessed. Recognition of caregivers' needs may positively impact the assistance that caregivers give as well as the outcomes of care recipients. 


\section{CHAPTER 3. METHODOLOGY}

This chapter outlines the methods used to address the primary aims presented in the current study. The discussion that follows describes the research design, sample and setting, the study instruments, data collection, general study procedures, the data analysis plan, and a discussion regarding the ethical issues related to the conduct of human research.

\section{Study Problem Overview}

The purpose of this study was to describe predictors of QoL of African American women who are caregivers of persons with ESRD. This study used a descriptive, predictive correlational design - a type of non-experimental quantitative design (Schmidt $\&$ Brown, 2012). Five purposes, derived from a review of literature and conceptual model, were used to guide this study. First, the study describes the association between demographic factors (i.e., education, employment, age, marital status), and QoL. Second, the study explores the relationship between stress and QoL. Third, the study describes the association between depressive symptoms and QoL. Fourth, the study describes the association between family health/happiness and QoL. Fifth, the study describes the extent to which demographic factors, stress, family health/happiness, and depressive symptoms predict QoL.

\section{Sample and Setting}

This secondary data analysis examines 75 African American women from an original study of 120 caregivers of persons receiving either maintenance in-center hemodialysis or home peritoneal dialysis. The primary investigator designed the original study to identify factors that predicted caregiver burden and caregiver health in persons assisting a relative who received dialysis. The original sample was recruited from three private physician-owned dialysis centers located in a southeastern region of the U.S. Males and non-African American caregivers were excluded from this secondary analysis because of the desire to investigate predictors of QoL of African American women, an understudied population of caregivers.

\section{Inclusion Criteria}

Inclusion criteria for the study were as follows.

- A primary family caregiver of persons with ESRD who receive in-center hemodialysis, home hemodialysis, or home peritoneal dialysis 
- $\quad$ An African American women caring for a person with ESRD who receives dialysis treatment from one of the three study sites

- Age 18 years or older at the time of enrollment in the original study

- Verbal and written consent to participate in the larger study of caregivers of persons with ESRD

- $\quad$ Able to read and speak English

\section{Exclusion Criteria}

Exclusion criteria for the study were as follows.

- Unable to speak or read English

- $\quad$ Caregivers of dialysis care recipients who were not African American

- Male caregivers of dialysis care recipients

- $\quad$ Caregivers of dialysis care recipients who had a non-functioning kidney transplant at the time of caregiver enrollment

- $\quad$ Caregivers of persons diagnosed with ESRD but who were not receiving dialysis

- $\quad$ Caregivers of dialysis care recipients with acute reversible renal failure

These criteria were used to assure that subjects could understand the study instruments and because of the team's desire to focus on a population over represented in the ESRD population but under-represented in family caregiving research. In addition, the study focused on the female caregivers as the most frequent caregivers and because acute dialysis is not associated with long-term caregiving. Finally, caregivers of care recipients with a failed transplant may report different experiences than caregivers who have not experienced transplantation as a type of renal replacement therapy.

\section{Instruments}

In the parent study, the participants completed questionnaires after receiving verbal instructions from the researcher. The current study involved a secondary analysis of data collected using the following instruments: The Caregiver Demographic Data Form, the Quality of Life Index (Ferrans \& Powers, 1985) the Family APGAR (Smilkstein, 1978), the Burden Interview Scale (Zarit, Reever, \& Bach-Peterson, 1980), and the Center for Epidemiological Studies Depression Scale (Radloff, 1977), and a single-item Likert question soliciting caregiver satisfaction with the social support 
received from family and friends. Each instrument is described in the succeeding paragraphs.

\section{Caregiver Demographic Data Form}

The Caregiver Demographic Data Form, a self-report and self-administered questionnaire, provides characteristics of the family caregiver and patient. The Caregiver Demographic form, written at a $6^{\text {th }}$ grade reading level, was developed by the principal investigator (T.T. Harris, 2003) of the parent study.

Demographic variables collected with this instrument included the caregiver's gender, race, age, marital status, income, education, and kinship or relationship to the care recipient (e.g., the person with ESRD). Family caregivers also provided data about the patient's gender, age, length of illness, living arrangements, dialysis type, and marital status. Estimated time to complete the items on the demographic data form was approximately five minutes.

\section{Quality of Life Index}

The Quality of Life (QLI) is a 32-item instrument that measures the QoL of healthy and ill persons. The instrument was written on a $4^{\text {th }}$-grade level. It was developed from a population of well-educated and upper-middle-class White men (Warnecke et al., 1996). The QLI measures areas of satisfaction and importance of various aspects of life. Importance ratings are used to weigh the satisfaction responses, so scores reflect the respondents' satisfaction with the aspects of life they value. Items ranked as more important have a greater influence on scores than those of lesser importance (Ferrans \& Powers, 1985).

The first section of the QLI measures satisfaction with various aspects of life and the second section measures the importance of those same aspects. Each section has 32 items (see Table 2-1).

The QLI uses a six-point rating scale that ranges from 6 (very satisfied) to 1(very dissatisfied) for the satisfaction items and 6 (very important) to 1 (very unimportant) for the importance items. Six-item response categories are used to maximize discrimination and reliability. The instrument produces five scores calculated for overall QoL and QoL in four domains: health and functioning, psychological and spiritual, social and economic, and family domains. The scores are determined by adjusting satisfaction responses for the importance responses to correct for varying influence of individual values; thus, a more accurate reflection of the subjects' QoL is produced. Scores range from $0-30$. Higher scores reflect a more favorable rating.

In a published study, the total QLI reliability coefficient for caregivers was .92 with the alpha coefficient for all sub-scales greater than .70 except for the social and 
economic domain. The alpha coefficient for this domain was .64 in a sample of primarily married female caregivers of patients with technologically dependent end-stage heart failure (Scott, 2000).

The QLI has content, convergent, and construct validity. Validity was determined by assessing a sample of 37 White male dialysis patients and a general sample of 88 graduate students (Ferrans \& Powers, 1985). Extensive literature review of issues relating to QoL and reports of factors that comprise QoL by dialysis patients support the content validity of the QLI. Factor analysis explained $91 \%$ of the total variance in the four dimensions underlying the QLI (health and functioning, social and economic, psychological and spiritual, and family domain). Analysis of the four factors also revealed one higher order factor that represented QoL. Construct validity of the QLI was also supported using a contrasted groups approach. Individuals were split into groups based on self-reported levels of depression, pain, and success in coping with stress. Individuals who experienced less pain, less depression, or who were coping well with stress had higher overall QLI scores. The same approach was also used to assess the construct validity of the social and economic subscale and showed higher QoL scores on the social and economic subscales in those with higher incomes (Ferrans \& Powers, 1985).

The instrument can be self-administered or administered in an interview format and takes 10 minutes to complete. No special training is needed to administer this test (Ferrans \& Powers, 1985).

\section{Family APGAR}

The Family APGAR, a 5-item interviewer-administered questionnaire developed by Smilkstein (1978), was used to assess the respondents' perception of family functioning by examining his or her satisfaction with family relationships. This instrument has a reading level of grade 5 .

The acronym "APGAR" is the first letter of each parameter of family functioning, which is: $\underline{A} d a p t a b i l i t y, \underline{P} a r t n e r s h i p, \underline{G} r o w t h, \underline{A} f f e c t i o n$, and $\underline{R}$ esolve. The instrument permits three possible responses, $(2,1,0)$ to each item on the questionnaire. The response options are designed to describe the frequency of feeling satisfied with each parameter on a 3-point scale ranging from 0 (hardly ever) to 2 (almost always). Adding the values for the items yields a total score that ranges from 0 to 20 . A higher score indicates greater satisfaction with family functioning. The time required to complete the questionnaire is less than 5 minutes.

Cronbach's alpha values described across studies using the Family APGAR have varied from .80 to .85 , and item-to-total correlations varied from .50 to .65 (Smilkstein, 1978). The author's initial validation of the instrument was achieved by establishing correlations with a previously validated instrument, the Pless and Satterwhite Index as well as with clinical reports from psychotherapists. The former yielded a correlation of 
.80 , the latter .64 (Pless \& Satterwhite, 1973; Smilkstein, 1978). This instrument was validated in a group of married graduate students who consisted of men and women with an average age of 19.7 years, and in a community, mental health clinic patients who were both male and female (Smilkstein, 1978).

High rates of disagreement between clinicians and the scale concerning positive cases were present. The Family APGAR was negative for $73 \%$ of families identified as dysfunctional by clinicians; however, $83 \%$ of families identified as dysfunctional were identified as not being dysfunctional by clinicians. Scores from the Family APGAR are derived from a single individual; therefore, data from other adults in the family or care recipients are not assessed using this instrument (Gardner et al., 2000). The internal consistency of the Family APGAR was .77 in primary caregivers of dependent relatives (Rodriguez-Sanchez et al., 2011). The time required to complete the questionnaire is less than 5 minutes (Smilkstein, 1978).

\section{Burden Interview}

The Burden Interview (BI), developed by Zarit et al. (1980) was designed to assess the subjective effect of caregiving. The BI scale has a $6^{\text {th }}$-grade reading level. The BI was originally developed to assess subjective burden in caregivers of persons with dementia. This instrument contains two subscales: personal and role strain scales. The subscales reflect two important aspects of caregiving: 1) how personally straining or stressful the experience is, and 2) stress due to role overload or conflict (role strain). The $\mathrm{BI}$ has a 5 -point rating scale $(0=$ never, $4=$ nearly always $)$, with composite scores for the full scale ranging from 0 to 88 . Composite scores ranging $0-20$ indicate little to no burden, scores of 21-41 reflect mild to moderate burden, scores of 41-60 suggest moderate to severe burden, and scores 61-88 indicate severe burden. Sub-scale scores for personal strain and role strain are 0 to 48 and 0 to 24 , respectively.

Internal consistency of the BI was .92 in a sample of African American primary caregivers of patients with dementia (Flynn-Longmire \& Knight, 2011). Additionally, the BI showed construct validity which was assessed using a three-factor confirmatory analysis in a study of a majority of African American and White caregivers of patients with dementia (Flynn-Longmire \& Knight, 2011). Only total scale scores will be reported in the current study sample.

\section{Center for Epidemiologic Studies Depression Scale}

The Center for Epidemiologic Studies Depression Scale (CES-D) is a short selfreport scale (Radloff, 1977) devised to measure depressive symptoms in the general population. The CES-D scale is written on a $6^{\text {th }}$-grade reading level.

The CES-D is based on clinical cases of depression although it was not created for clinical diagnosis. This scale measures current levels of depressive symptoms with the 
emphasis on the affective component. The CES-D includes 20 items comprising six scales reflecting major dimensions of depression: feelings of guilt and worthlessness, feelings of helplessness, depressed mood, loss of appetite, sleep disturbances, feelings of hopelessness and psychomotor retardation. Respondents are asked to rate on the inquiry of "how often you have felt this way during the past week?" Response categories indicate the frequency each item occurs and are scored on a 4-point scale ranging from 0 (rarely or none at the time) to 3 (most or all of the time). Scores for items 4, 8, 12, and 16 are reversed before scoring all items to yield a total score. Total scores range from 0 to 60. Higher scores (both item and total scores) suggest more frequent depressive symptoms as items reflect the respondents' experiences for the past week (Radloff, 1977). A score of 16 or more is used as the cut-off point for high depressive symptoms on this scale as it suggests the need for further evaluation (Perreira, Deeb-Sossa, Harris, $\&$ Bollen, 2005). Cronbach's alpha for the CES-D in a sample of African American female caregivers of elderly patients was .83 (Rozario \& Menon, 2010). Internal consistency was high in the general population (.85) and high in a patient sample (.90). Test-retest correlations were between .45 and .70 (Radloff, 1977).

Depression is reported lower in African American caregivers compared to White caregivers in some studies; however, when race and living arrangements are considered, the CES-D detects significant depression in African American caregivers who live with the care recipient (Siegler, Brummett, Williams, Haney, \& Dilworth-Anderson, 2010). CES-D has content, criterion, construct validity, and discriminant validity. The major components of the scale were taken from factor analysis from the clinical literature. The scale discriminated with clinically depressed inpatients and the general population (Radloff, 1977). Moreover, the validity of the CES-D was examined in a population of African American women who are family caregivers of elders using confirmatory factor analysis (Rozario \& Menon, 2010). The four factors for the model included depressed affect, positive affect, somatic complaints, and interpersonal relations. Makambi, Williams, Taylor, Rosenberg, and Adams-Campbell (2009) found that the CES-D scale was appropriate for use in African American women when they used a four-factor model with magnitudes above .43. Correlation in the group ranged between .43 for interpersonal and positive and .90 for somatic affect and depressed affect (Makambi et al., 2009).

The item-total correlation among these items ranged from .30 to .60 . The fit indices showed that the four measurement models converged; however, the fit indices did not indicate a good fit. In the four-factor model, six items explained $70 \%$ of the factor variance for depressed affect; six items explained $48 \%$ of the factor variance for somatic complaints; four items explained $68 \%$ of the factor variance for positive affect; and two items explained $76 \%$ of the factor variance for interpersonal relations (Rozario \& Menon, 2010). These data support the construct validity of the measure. 


\section{Data Analysis}

\section{Selection of Participants}

The participants in this study were selected based on the information provided in the original study of caregivers of persons with ESRD (T.T. Harris, 2003). To identify patients' primary caregiver, the patients in the dialysis centers, were asked, "If you become unable to care for yourself whom would you ask to take care of you?" The principal investigator (PI) in the current study was given de-identified data with Institutional Review Board (IRB) approval for all participants who met the inclusion criteria. The dataset did not include the participant's birthdates, social security numbers, or other personal identification that could link specific participants to the dataset information. The PI was not allowed to view the consent forms from the larger study.

\section{Data Analysis}

The data used from the original study were maintained on a Microsoft Excel spread sheet, and analyzed using Statistical Package for the Social Sciences 22.0 (SPSS) computer software. The level of significance was set at .05 for all analyses except the bivariate correlational analyses conducted to identify predictor variables in the regression model. For the regression model, the p-value was set at .20. The specific statistical test used for each aim is described below.

Initially descriptive statistics were completed to determine the sample demographic characteristics. Measures of central tendency, (i.e., mean and median), and variability (i.e., range and standard deviation) were performed. The caregiver demographic information analyzed was age, marital status, income, hours of care provided, number of months of care provided, education, hours worked, and residential status, and relationship to patient. These independent variables were coded as either continuous or categorical. Pearson's r coefficient were computed to examine relationships between QoL (as measured by the QLI) and caregivers' demographic characteristics, depressive symptoms, stress, and family health/happiness. One-way ANOVA on ranks (Kruskal Wallis) was used to determine the relationship between QoL and predictor variables with three or more response categories (i.e., employment status). Independent samples t test was used to determine the relationship between QoL and predictor variables with two response categories (i.e., marital status). following.

In African American women who are caregivers of persons with ESRD we did the

- $\quad$ Primary aim one was to describe the association between QoL and demographic factors (such as, education, employment, age, marital status).

- $\quad$ Primary aim two was to describe the association between QoL and stress. 
- $\quad$ Primary aim three was to describe the association between QoL and depressive symptoms."

- $\quad$ Primary aim four was to describe the association between QoL and family health and happiness.

In African American women who are caregivers of persons with ESRD we used multiple regression analysis to achieve primary aim five, which is: Described the degree to which demographic factors, stress, family health/happiness, and depressive symptoms predicted overall QoL in African American women who care for persons with ESRD.

\section{Protection of Human Participants}

The current study received approval from the University of Tennessee Health Science Center IRB IRB\#14-03087-XM (Appendix). The dialysis centers' medical director also gave written, in the form of a letter, and verbal approval to recruit caregivers at the dialysis centers. Data were collected before the current establishment of patient privacy guidelines. Additionally, the participants in the original study (T.T. Harris, 2003) gave written and verbal informed consent. Because this study was a secondary data analysis, there were no emotional, physical, or legal risks involved in the current study of de-identified data and none were reported in the original study (T.T. Harris, 2003). 


\section{CHAPTER 4. PREDICTORS OF QUALITY OF LIFE IN AFRICAN AMERICAN WOMEN WHO ARE CAREGIVERS OF PERSONS WITH END STAGE RENAL DISEASE}

\section{Introduction}

African American caregivers disproportionately support persons diagnosed with ESRD (United States Renal Data System, 2015). Women in the U.S. are the primary providers of support to family members with chronic health care needs (Family Caregiver Alliance: National Center on Caregiving, 2015). African American caregivers who are women are usually older and "sandwiched" between caring for their young children and the elderly (National Alliance for Caregiving, 2009) and may be at particular risk for poor quality of life (QoL). The average age in the U.S. for new persons starting renal replacement therapy is about 64 years, and the most common form of therapy is hemodialysis (United States Renal Data System, 2015). Thus, caregivers of care recipients with end stage renal disease are faced with the challenge of providing complex care to family members with ESRD, and the care recipient may be an older relative.

Caregiving has the potential to affect negatively caregivers' QoL. Evaluation of caregivers' QoL has become a new priority because researchers have recognized that the quality of care that is provided to care recipients is associated with the caregivers' QoL (Belasco et al., 2006; Ferrans et al., 2005; Rees et al., 2001). Many leading national organizations such as The World Health Organization (2012), Office of Disease Prevention and Health Promotion (2014b), and the Centers for Disease Control and Prevention (2009) have all emphasized the importance of measuring QoL in all individuals. Studies have reported that compared to non-caregivers and care recipients, informal caregivers report the poorest QoL (Çelik et al., 2012; Haley et al., 2015; Mellon et al., 2006; Spencer et al., 2013). However, not much is known about the QoL of African American women who are caregivers of persons with ESRD. Many studies that have assessed QoL in the context of ESRD in recent years focused on children with chronic kidney disease (Kilis-Pstrusinska et al., 2013; McKenna et al., 2006) and children with donor kidneys (Tsai et al., 2006). Additionally, researchers have assessed QoL of caregivers of care recipients who use peritoneal dialysis (Fan et al., 2008) and kidney transplant (Rodrigue et al., 2010). Many investigators from other countries such as Brazil (Belasco et al., 2006), Japan (Shimoyama et al., 2003), and Thailand (Limpanichkul, 2004) have also examined caregivers' QoL in the context of ESRD. Thus, the importance of assessing caregiver QoL is a worldwide phenomenon.

The lack of a significant number of studies that have assessed QoL in the context of ESRD of caregivers who are African American women is surprising considering the illness disproportionally affects African Americans (United States Renal Data System, 2015). African Americans make up about $15 \%$ of the population (Centers for Disease Control, 2015), but comprise 32\% of the cases of ESRD (United States Renal Data System, 2015). However, individuals who receive hemodialysis experience more 
treatment-related difficulty than those who receive other types of renal replacement therapy.

\section{Background and Significance}

Assisting a family member who has ESRD requiring dialysis may cause significant changes that can affect a caregiver's QoL (Gill et al., 2011). Quality of Life considers how one perceives all aspects of life including social, economic, family, spiritual, and health aspects of life (Centers for Disease Control and Prevention, 2011). However, not much is known about the factors that affect QoL, among African American women caring for persons with ESRD (Houser \& Gibson, 2008). Many QoL studies have focused on patient outcomes (Lefaiver et al., 2009), or have focused on a single outcome (i.e., burden, anxiety, fatigue, depression) experienced by caregivers of persons with ESRD (Tong, Sainsbury, \& Craig, 2008). Measuring QoL may more accurately address the multidimensional and complex roles of caregivers rather than a single outcome measure such as burden and depression.

Researchers and national organizations have reported that caregivers' health worsens, or that caregivers' risk of health problems increases after assuming the role (Lefaiver et al., 2009). Caregivers' health declines because they neglect their needs and focus on the care recipients' needs (Meecharoen et al., 2013; Teschendorf et al., 2007). Caregivers have more suppressed immune systems, more chronic and untreated health conditions, higher levels of stress hormones, higher risk of heart disease, and are more likely to smoke and engage in unhealthy lifestyle habits than non-caregivers (Family Caregiver Alliance: National Center on Caregiving, 2006). Thus, it is not surprising that caregiving is viewed as an independent risk factor for increased morbidity and mortality among caregivers of elderly spouses (Family Caregiver Alliance: National Center on Caregiving, 2006; Schulz \& Beach, 1999).

Culture, traditions, values and norms have supported the obligation of women to provide care for ethnic minorities such as African Americans (Black \& Peacock, 2011; Meecharoen et al., 2013; Pharr et al., 2014). There are many differences in factors that affect the QoL in caregivers. For instance women of all ethnicities who provide care to ill persons may experience significant stress, and are more likely to have lower QoL than men (National Alliance for Caregiving, 2005;(M.H. Bellin et al., 2013). However, African American women experience more health disparities than any other ethnic group in the U.S. (Centers for Disease Control, 2015). Time-consuming caregiving tasks can limit self-care which may worsen health risks for African American women (Office of Women's Health, 2012). African American women are at a dangerously elevated risk for negative health consequences because of the added stress of caregiving. Currently, African American women lead the U.S. in more maternal deaths than developing countries, delays in treatment for cancer, obesity, new cases of HIV, and hypertension (National Coalition on Black Civic Participation: Black women's'roundtable, 2014). 
Thus, the goal of the current study was to determine the QoL of the participants and to determine factors that predict it. These factors reflect the domains as per Ferrans' Conceptual Model for Quality of Life (Ferrans, 1996), and include stress, depressive symptoms, demographic factors (i.e., education, employment status, age), and family health/happiness. We did not examine individual subscale scores.

\section{Conceptual Model}

According to Ferrans' Conceptual Model for Quality of Life (Ferrans, 1996), people place value on different things and have different perceptions of their QoL and have differences in QoL. A subjective and multidimensional concept, QoL quantifies caregivers' perceptions. Moreover, QoL has been used to assess the effectiveness of treatments and interventions. The understanding is unclear about the factors that contribute to the QoL of African American women who are caregivers of persons with ESRD. We think it is necessary to examine factors that can affect caregivers of care recipients who are diagnosed with other chronic illnesses to understand the QoL of this understudied population.

The conceptual model was created by Ferrans (1996). The model was developed from extensive literature review, and patient interview, and was designed to measure QoL in terms of satisfaction with life (Ferrans, 1996).

Ferrans' Conceptual Model for QoL (Figure 2-1) is composed of four domains, a) health and functioning, b) psychological and spiritual, c) social and economic, and d) family domains. The elements of the model are listed in Table 2-1.

\section{Review of Literature}

\section{Health and Functioning and Quality of Life}

African American women may not experience high levels of stress as a result of caregiving. Findings from several cross-sectional studies found that African American women report little to no stress when they provide care for persons with chronic illnesses like with care recipients with cancer (Powe et al., 2013), and care recipients with serious mental illnesses (Zauszniewski et al., 2009). Furthermore, African American women who report little no stress have favorable QoL. For example, with caregivers of adults with heart failure (Saunders, 2009), post-stroke care recipients (Clay et al., 2013), and dementia care recipients (Kaufman et al., 2010) experienced poor QoL as their stress increased. Nonetheless, African American women who are caregivers' QoL and stress seem to improve the longer they provide care (M. H. Bellin et al., 2015). Studies consistently show that caregivers from ethnic minority groups who are overwhelmed and unprepared for their role experience poor QoL. For instance, caregivers of adult persons with a donor lung (Lefaiver et al., 2009), or children with a chronic lung disorder (Feeley 
et al., 2014) were overwhelmed with caregiving responsibilities. This feeling of being overwhelmed may affect caregivers' usefulness to others.

Moreover, caregivers report fatigue related to caregiving activities. One qualitative study found that ethnic minority caregivers of persons with a donor's lung experienced exhaustion from their role (Lefaiver et al., 2009). Many caregivers experience insomnia; thus, fatigue may result from poor quality sleep (Feeley et al., 2014; Powe et al., 2013). Inadequate sleep was shown to impair QoL in African American women who were caregivers of breast cancer survivors (Powe et al., 2013). Fatigue and insomnia may have a psychological etiology. Physical and psychological factors interrelate. For instance, caregivers who suffer from depression have more sleep problems and chronic illnesses (Feeley et al., 2014). Caregivers may experience a myriad of symptoms because they often neglect their health care needs.

In one cross-sectional study, African American and White caregivers of heart failure care recipients who themselves had health problems reported poor QoL (Saunders, 2009). Other studies reported that African American caregivers with poor physical health experienced poorer QoL than Whites (Feeley et al., 2014; Zauszniewski et al., 2009). One longitudinal study compared African American and White caregivers of persons poststroke over a period of three years (Haley et al., 2015). These researchers found that caregivers' QoL declined over a period of three years when they experienced many physical health problems (Haley et al., 2015).

\section{Social and Economic and Quality of Life}

Social and economic factors are critical factors in predicting women's QoL. Health, income, and illness lie on a social gradient in which those who are socially disadvantaged suffer from more diseases have less access to resources and services and have higher mortality rates. Women make less money than men, despite possessing high levels of education. Stress and other psychological problems are often the direct result of low SES (American Psychological Association, 2015).

African American women have high participation in the workforce, yet continue to receive unequal pay, and have the lowest household income among other ethnicities in the U.S, and less social security benefits (National Coalition on Black Civic Participation: Black women's'roundtable, 2014). To add, African American women experience more difficulty taking time off from work than Caucasians and Hispanics (Siefert et al., 2008) and may have less income when they do take time off from work. These social and economic conditions may explain the reason M.H. Bellin et al. (2013) found that African American women with higher education experience poor QoL (M.H. Bellin et al., 2013). However, Anaforoglu, Ramazanogullari, Algun, and Kutanis (2012) and Mellon et al. (2006) found that African American women who are employed, have higher incomes, or other financial benefits (Kaufman et al., 2010) report higher QoL than caregivers who are unemployed (Mellon et al., 2006; Roth et al., 2009). Women in families assume the role of caregiver because of gender role socialization especially in ethnic minority groups 
(Meecharoen et al., 2013; Roth et al., 2009). In contrast, men are typically neither assigned responsibility nor held accountable for caregiving duties (Berg \& Woods, 2009). Women who are caregivers tend to have multiple roles and multiple responsibilities for other family members.

Social support may be protective of adverse effects of caregiving in African American women. For example, researchers have reported that African American women who care for care recipients with dementia (Kaufman et al., 2010) and cancer (Mellon et al., 2006) experienced favorable QoL when they received social support from family and friends.

\section{Psychological and Spiritual and Quality of Life}

The QoL reported by African American women may be affected by spiritual and religious factors. Giger and colleagues (Giger, Appel, Davidhizar, \& Davis, 2008) as well as Pittman (2012) suggest that the African American church, spirituality, and religion promote good QoL; however, an extensive literature review showed no relationship between religion and spirituality and caregivers' QoL (Hebert et al., 2006).

High levels of depressive symptoms have been reported to result in poor QoL in caregivers of care recipients with chronic illnesses such as breast cancer and type 2 diabetes and caregivers of people with Type 2 diabetes (Anaforoglu et al., 2012; Heidari Gorji et al., 2012). Caregivers who resent care usually live with the care recipient and have more depressive symptoms than caregivers who do not reside with care recipients (Aggar, Ronaldson, \& Cameron, 2011) and African American women often live with the care recipient. However, researchers share the assumption that African American caregivers possess resilience and typically experience less depression in response to caregiving than Whites (American Psychiatric Association, 2009; Clay et al., 2013; Haley et al., 2015; Roth et al., 2009). In one study, researchers reported that African Americans had better psychological outcomes (i.e., low depressive symptoms) than Whites when caring for care recipients who suffered from a stroke (Clay et al., 2013). Psychological outcomes do not seem to change for African American women over time while in the role as caregiver. For instance, the impact of stroke on caregivers' QoL and depression was examined over a three-year period, and African American women experienced less depression than Whites even though their care recipients experienced greater impairments in health (Haley et al., 2015). The role of a caregiver may provide reward and satisfaction for African Americans. Caregiving is seen as a reward because caregivers can establish closer relationships with the care recipient. Caregiving also allows African Americans the ability to express reciprocity in their relationships. Caregiving, often seen as a unique opportunity, helps some individuals discover new meaning in life, and helps personal growth (Teschendorf et al., 2007). 


\section{Family and Quality of Life}

Chronic illness can affect a family's functioning and the quality of care that caregivers offer (Rodriguez-Sanchez et al., 2011). For example, caregivers of dependent children-care recipients who were satisfied with family functioning experienced excellent QoL (Rodriguez-Sanchez et al., 2011). Caregiving in ethnic minority families, such as African American, Hispanic, and Asian populations include close friends, and neighbors in their family networks (Pharr et al., 2014). Extended kinship networks in African American families have traditionally shared responsibility for others within their communities because of historical oppressions (Pharr et al., 2014; Pittman, 2012). Ethnic minorities often hold a cultural and traditional rationale for giving care to other family members (Pharr et al., 2014).

When people in families become ill, family members may assign responsibility to one individual to care for the person. The assignment of roles may create conflicts among members of the family. Most caregivers of older care recipients report that caregiving duties do not affect their health. They also report low-stress levels; however, they report that they have less time for other family members and friends and themselves (National Alliance for Caregiving \& AARP, 2009).

Thus, not only may some African American women caregivers assist a family member, but a large number of them may also help friends and neighbors. Declination of caregiving responsibilities is often viewed negatively and culturally unacceptable (Pharr et al., 2014).

\section{Purpose of Study}

The primary aims of this study were to describe the association between overall QoL in African American woman caring for a person with ESRD and demographic factors (i.e., education, employment, age, marital status), stress, happiness, and family health and happiness. We also sought to determine the degree to which demographic factors, stress, depressive symptoms and family health and happiness predict QoL.

\section{Methods}

This study used a descriptive, predictive, correlational design to analyze data from 75 African American women who were caregivers of persons with ESRD who received either maintenance in-center hemodialysis or home hemodialysis, or home peritoneal dialysis (T.T. Harris, 2003). The current study received approval (IRB\#14-03087-XM) from The University of Tennessee Health Science Center's Institutional Review Board (IRB).

To identify patients' primary caregiver, the patients in the dialysis centers, were asked, "If you become unable to care for yourself whom would you ask to take care of 
you?" To qualify for the current study, participants needed to function as the primary family caregiver of persons with ESRD receiving in-center hemodialysis, home hemodialysis, or home peritoneal dialysis, an African American woman caring for a person with ESRD who was receiving dialysis treatment from one of the three study sites, age 18 years or older when enrollment in the original study, and gave verbal and written consent to participate in the larger study of caregivers of persons with ESRD. Participants were required to read and speak English.

\section{Caregiver Demographic Data Form}

The Caregiver Demographic Data Form (CDD) provided characteristics of the family caregiver. Demographic variables collected by this instrument include the caregiver's gender, race, age, marital status, income, education, and relationships to the person with ESRD. Estimated time to complete the items on the demographic data form was approximately five minutes (T.T. Harris, 2003). The CDD is a self-reported and selfadministered questionnaire that was developed by the principal investigator of the original study. The Caregiver Demographic Data Form is written at a $6^{\text {th }}$-grade reading level.

\section{Quality of Life Index}

The Quality of Life Index (QLI), developed by Ferrans and Powers (1985) was used to measure QoL. The QLI consists of two sections. The first section measures satisfaction with various aspects of life and the second measures importance of those same aspects. Thirty-two items of the QLI are divided into the four domains: a) health and functioning, b) psychological and spiritual, c) social and economic, d) and family. (Table 2-1).

Importance ratings are used to weigh the satisfaction responses, so scores reflect the respondents' satisfaction with the aspects of life they value. Items that are rated as more important have a greater influence on scores than those of lesser importance. The items are in a six-point Likert scale ranging from 6 (very satisfied) to 1 (very dissatisfied) for the satisfaction items, and 6 (very important) to 1 (very unimportant) for the importance items.

The scores are determined by adjusting satisfaction responses for the importance responses to correct for varying influence of individual values, thus producing a more accurate reflection of the subjects' QoL. Scores range from 0-30. Higher total scores reflect high QoL.

The QLI has content, convergent, and construct validity. The instrument can be self-administered or administered in an interview format. It takes about 10 minutes to complete. No special training is needed to administer this test. The instrument is written on a $4^{\text {th }}$-grade reading level (Ferrans \& Powers, 1988). 


\section{Family APGAR}

The Family APGAR, a 5-item interviewer-administered questionnaire developed by Smilkstein (1978), was used to assess the respondents' perception of family functioning by examining his or her satisfaction with family relationships. The Family APGAR was used to operationalize family health and happiness in the current study. The acronym "APGAR" denotes the first letter of each parameter of family functioning, which is: Adaptability, Partnership, Growth, Affection, and Resolve. The instrument permits three possible responses, $(2,1,0)$ to each item on the questionnaire. The response options are designed to describe the "frequency of feeling satisfied with each parameter on a 3-point scale ranging from 0 (hardly ever) to 2 (almost always)."Adding the values for the items yields a total score that ranges from 0 to 10." A higher total score indicates a greater degree of satisfaction with family functioning. The time required to complete the questionnaire is less than 5 minutes (Smilkstein, 1978). The internal consistency of the Family APGAR was .77 in caregivers of dependent relatives (Rodriguez-Sanchez et al., 2011). This instrument has a $5^{\text {th }}$-grade reading level.

\section{Burden Interview}

The Burden Interview, developed by Zarit et al. (1980), measures subjective burden. The BI was used to operationalize stress in the current study. The BI was originally designed to assess subjective burden in caregivers of persons with dementia. This instrument contains two subscales: personal and role strain scales. The subscales reflect two important aspects of caregiving: 1) how personally straining or stressful the experience is and 2) stress due to role overload or conflict (role strain). The BI has a 5point rating scale $(0=$ never, $4=$ nearly always $)$, with composite scores for the total scale ranging from 0 to 88 . Composite scores ranging 0-20 indicate little to no burden, scores of 21-41 reflect mild to moderate burden, scores of 41-60 suggest moderate to severe burden, and scores 61-88 indicate severe burden. Sub-scale scores for personal strain and role strain are 0 to 48 and 0 to 24, respectively. Internal consistency of the BI was .92 in a sample of African American primary caregivers of patients with dementia (FlynnLongmire \& Knight, 2011). Additionally, the BI showed validity which was assessed using a three-factor confirmatory analysis in a study of a majority of African American and White caregivers of patients with dementia (Flynn-Longmire \& Knight, 2011). The BI scale has a $6^{\text {th }}$-grade reading level.

\section{Center for Epidemiologic Studies Depression Scale}

The Center for Epidemiologic Studies Depression Scale (CES-D) is a short selfreport scale (Radloff, 1977) that was used to measure caregivers' depressive symptoms. The CES-D was used to operationalize the absence of happiness in the current study. The CES-D is based on clinical cases of depression although it is not used for diagnosis. This scale measures current levels of depressive symptoms with the emphasis on the affective 
component. The CES-D includes 20 items comprising six scales reflecting major dimensions of depression: feelings of guilt and worthlessness, feelings of helplessness, depressed mood, loss of appetite, sleep disturbances, feelings of hopelessness, and psychomotor retardation. Respondents are asked to rate on the inquiry of "how often you have felt this way during the past week?" "Response categories indicate the frequency of occurrence of every item and are scored on a 4-point scale ranging from 0 (rarely or none at the time) to 3 (most or all of the time)." The total possible score for the CES-D is 60 . Higher scores (item and total scores) indicate more frequent depressive symptoms as items reflect the respondents experiences for the past week (Radloff, 1977). A score of 16 or more is used as the cut-off point for high depressive symptoms on this scale as it suggests the need for further evaluation (Perreira et al., 2005). Cronbach's alpha for the CES-D in a sample of African American women who are caregivers of elderly patients was .83 (Rozario \& Menon, 2010). Internal consistency was high in the general population (.85) and high in a patient sample (.90). Test-retest correlations were between .45 and .70 (Radloff, 1977). The CES-D scale is written on a $6^{\text {th }}$-grade reading level.

\section{Data Analysis}

First, descriptive statistics were performed to determine the characteristics of the sample. Secondly, research aim 1 through 4 were analyzed using Pearson's $r$ coefficient, to examine relationships between QoL and caregivers' demographic characteristics, depressive symptoms, stress, and family health/happiness. One-way ANOVA on ranks (Kruskal-Wallis) was used to determine the relationship between QoL and predictor variables with three or more response categories. Independent samples t-test was used to determine the relationship between QoL and predictor variables with two response categories.

Multiple linear regression analysis - 3 step-types (backward elimination, forward selection, and stepwise) was used to address aim 5. The data in the current study were analyzed using Statistical Package for the Social Sciences 22.0 (SPSS) computer software.

\section{Results}

Table 4-1 and Table 4-2 present a descriptive analysis of the characteristics of the sample. All caregivers $(\mathrm{N}=75)$ were African American women. The sample was educated, mostly not married, caring for a spouse or parent. Many of the caregivers were employed, and lived with the care recipient. Table 4-3 provides a summary of scores for each predictor variable and QoL. 
Table 4-1. Description of Demographic Characteristics of Caregivers.*

\begin{tabular}{|c|c|c|}
\hline Variables & $\mathrm{n}$ & $\%$ \\
\hline \multicolumn{3}{|l|}{ Marital status } \\
\hline Not married & 44 & 58.7 \\
\hline Married & 31 & 41.3 \\
\hline \multicolumn{3}{|l|}{ Employment } \\
\hline Full-time & 33 & 44.0 \\
\hline Part-time & 11 & 14.7 \\
\hline Unemployed & 31 & 41.3 \\
\hline \multicolumn{3}{|l|}{ Education } \\
\hline$<$ High school & 2 & 2.7 \\
\hline Some high school & 37 & 49.3 \\
\hline Some college & 36 & 48.0 \\
\hline \multicolumn{3}{|l|}{ Recipients' Relationship } \\
\hline Husband & 24 & 32.0 \\
\hline Child & 7 & 9.3 \\
\hline Parent & 28 & 37.3 \\
\hline Sibling & 5 & 6.7 \\
\hline Other & 11 & 14.7 \\
\hline \multicolumn{3}{|l|}{ Reside with Recipient } \\
\hline Yes & 47 & 62.7 \\
\hline No & 28 & 37.3 \\
\hline \multicolumn{3}{|l|}{ Support } \\
\hline Very satisfied & 34 & 45.3 \\
\hline Satisfied & 19 & 25.3 \\
\hline Somewhat satisfied & 13 & 17.3 \\
\hline Dissatisfied & 6 & 8.0 \\
\hline Very dissatisfied & 3 & 4.0 \\
\hline
\end{tabular}

Table 4-2. Means and Ranges of Demographic Characteristics. ${ }^{a}$

\begin{tabular}{|c|c|c|}
\hline Characteristic & $M(S D)$ & Range \\
\hline $\operatorname{Age}^{b}$ & 46.9 (13.8) & $19-77$ \\
\hline Months of care & $49.0 \quad(55)$ & $1-336$ \\
\hline Hours of care & $27.0 \quad(27)$ & $0-168$ \\
\hline
\end{tabular}

Notes. ${ }^{a} \mathrm{~N}=75$; ${ }^{\mathrm{b}}$ Age measured in number of years. Hours of care provided per week. 
Table 4-3. Mean and Ranges of all Measures. ${ }^{a}$

\begin{tabular}{lccc}
\hline \multicolumn{1}{c}{ Measures } & M (SD) & $\begin{array}{c}\text { Range of } \\
\text { Participants' } \\
\text { Scores }\end{array}$ & $\begin{array}{c}\text { Range of } \\
\text { Possible Scores }\end{array}$ \\
\hline $\begin{array}{l}\text { Quality of Life Index } \\
{ }^{\mathrm{b}}\end{array}$ & $16.6(1.4)$ & $15-20$ & $0-30$ \\
Family APGAR $^{\mathrm{c}}$ & $15.2(5.0)$ & $0-20$ & $0-20$ \\
Burden Interview $^{\mathrm{d}}$ & $18.0(14.0)$ & $0-59$ & $0-88$ \\
$\mathrm{CES}-\mathrm{D}^{\mathrm{e}}$ & $20.3(9.4)$ & $0-48$ & $0-60$ \\
\hline Notes. $^{\mathrm{a}} \mathrm{N}=75$; $^{\mathrm{b}}$ Quality of life measured by Quality of Life Index; ${ }^{\mathrm{c}}$ Family APGAR \\
measured family functioning. In the current study family health/happiness was \\
operationalized as family functioning; ${ }^{\mathrm{d}}$ Burden Interview measures caregiver burden. In \\
the current study stress was operationalized as caregiver burden. ${ }^{\mathrm{e}} \mathrm{CES}-\mathrm{D}$ measures \\
depressive symptoms. In the current study happiness was operationalized as absence of \\
depression.
\end{tabular}




\section{Correlations of Study Variables}

Table 4-4 presents a bivariate analysis of QoL by hours worked, months of care, hours of care, age, and education. Pearsons' $r$ indicated a statistically significant relationships between caregiver QoL and caregivers' hours worked, caregivers' age hours of care, and education, Table 4-5 presents a bivariate analysis of QoL by educational level, recipients' relationship with the caregiver, and satisfaction with support received. One-way ANOVA indicated statistically significant differences between the means scores of educational level, relationship to the caregiver, employment status, and support. Table 4-6 presents an analysis of QoL by whether or not caregivers reside with care recipients. An independent t-test indicated that the mean QoL score was higher in caregivers who did reside with care recipients than those who reported not living with care recipients. Table 4-7 presents the correlations between QoL and stress, depression symptoms, and satisfaction with family health/happiness. Pearsons' $r$ coefficients indicated a statistically significant association between caregiver QoL and family health and happiness and stress. Thus, better overall QoL was significantly associated with greater satisfaction with family health and happiness, and less stress.

\section{Predictors of QoL}

Before running the regression analysis, categorical data were dummy coded Table 4-8 where the presence of a characteristic was coded 1 and absence of a characteristic was coded 0 . Results of the multiple regression analysis are in Table 4-9. The data were analyzed by multiple regression using caregiver age, employment, marital status, education, stress, depressive symptoms, and family functioning as the predictors of the care QoL (Table 4-8). The predictors explained 62\% of the variance in QoL (F = $16.02, \mathrm{p}<0.0001)$. With other variables held constant, caregiver QoL was negatively related to caregiver employment status (full-time: $\mathrm{t}=-7.78, \mathrm{p}<0.0001$; part time: $\mathrm{t}=$ $5.26, \mathrm{p}<0.0001)$ and to stress (measured as total caregiver burden) $(\mathrm{t}=-3.29, \mathrm{P}=0.002)$.

We performed three, step-type multiple regression analyses (backward elimination, forward selection, and step-type regression) to get an optimal model for QoL. Predictor variables included marital status, caregiver education, full-time employment, part-time employment, and stress. Using the Step-Type Regression (Backward Elimination), the optimal model is shown in Table 4-10. The regression equation explained 63\% of variance in caregiver QoL $(F=19.26, p<0.0001)$. All the predictors were statistically significant. With other variables held constant, caregiver QoL was negatively related to caregiver education $(\mathrm{t}=-2.18, \mathrm{p}=0.033)$, to caregiver employment status (full-time: $\mathrm{t}=-8.47, \mathrm{p}<0.0001$; part-time: $\mathrm{t}=-5.54, \mathrm{p}<0.0001$ ) and to caregiver stress (measured as total burden) $(\mathrm{t}=-4.903, \mathrm{P}<0.0001)$; and was positively related to caregiver marital status $(\mathrm{t}=2.77, \mathrm{p}=0.007)$. Thus, QoL in African American women seems to be largely influenced by social determinants, and stress that can be categorized as both a physiological/psychological problem. 
Table 4-4. Correlation Coefficients: Relationship between Quality of Life and Caregiver Demographics. ${ }^{\mathrm{a}}$

\begin{tabular}{lcccccc}
\hline \multicolumn{1}{c}{ Variable } & $\begin{array}{c}\text { Quality } \\
\text { of Life }\end{array}$ & $\begin{array}{c}\text { Hours } \\
\text { Worked }\end{array}$ & $\begin{array}{c}\text { Months } \\
\text { of Care }\end{array}$ & $\begin{array}{c}\text { Hours } \\
\text { of Care }\end{array}$ & $\begin{array}{c}\text { Age } \\
\text { Education }\end{array}$ \\
\hline Quality of life $^{\mathrm{b}}$ & - & $-.65^{*}$ & .35 & $.34^{*}$ & $.36^{*}$ & $-.25^{*}$ \\
Hours worked $^{\mathrm{c}}$ & $-.65^{*}$ & - & -.59 & -.20 & $-.32^{*}$ & $.23^{*}$ \\
Months of care $^{\mathrm{c}}$ & .35 & -.59 & - & $.10^{*}$ & .14 & $.24^{*}$ \\
Hours of care $^{\mathrm{c}}$ & $.34^{*}$ & -.20 & $.10^{*}$ & - & .06 & .10 \\
Age $^{\mathrm{c}}$ & $.36^{*}$ & $-.32^{*}$ & .14 & .06 & - & -.97 \\
Education $^{\mathrm{c}}$ & $-.25^{*}$ & $.23^{*}$ & $.24^{*}$ & -.10 & -.97 & -
\end{tabular}

Notes. ${ }^{\mathrm{a}} \mathrm{N}=75$; ${ }^{\mathrm{b}} \mathrm{Quality}$ of life measured by Quality of Life Index; ' hours worked, months of care, hours of care per week, age, and education in years measured on the Caregiver Demographic Data Form; *p-value significant at the .05 level. Pearson's r was used to calculate the correlation coefficient.

Table 4-5. One-way ANOVA of Caregiver Demographic Characteristics by ${ }^{\text {a QoL. }}{ }^{\text {b }}$

\begin{tabular}{lccc}
\hline \multicolumn{1}{c}{ Variable } & $\mathrm{M}(\mathrm{SD})$ & $\mathrm{t} / \mathrm{F}(\mathrm{df})$ & $\mathrm{p}$ \\
\hline Educational Level $^{\mathrm{c}}$ & & $5.6(2,72)$ & $.01^{*}$ \\
$\quad$ Less high school & $19.50(0.70)$ & & \\
$\quad$ Some high school & $16.72(1.40)$ & & \\
$\quad$ Some College & $16.31(1.22)$ & & \\
Recipient Relationship & & & \\
$\quad$ Husband & & $3.0(4,70)$ & $.02^{*}$ \\
Child & $16.94(1.67)$ & & \\
Parent & $17.69(1.65)$ & & \\
Sibling & $16.17(1.09)$ & & \\
Other & $17.20(1.82)$ & & \\
Support & $15.98(.44)$ & & \\
$\quad$ Very satisfied & & $10(4,70)$ & $.00^{*}$ \\
$\quad$ Satisfied & $17.53(1.60)$ & & \\
$\quad$ Somewhat satisfied & $16.03(0.59)$ & & \\
$\quad$ Dissatisfied & $15.74(0.51)$ & & \\
$\quad$ Very dissatisfied & $15.46(0.25)$ & & \\
\hline
\end{tabular}

Note. ${ }^{a}$ Quality of life measured by the Quality of Life Index; ${ }^{b} \mathrm{~N}=75 ;{ }^{c}$ Educational level, recipient relationship, and support measured on the Caregiver Demographic Data Form, ${ }^{*}$ p-value is significant at .05 level. 
Table 4-6. Independent Samples t-test of QoL by Residential and Marital Status. ${ }^{a}$

\begin{tabular}{lccc}
\hline Variable & $\mathrm{M}(\mathrm{SD})$ & $\mathrm{t} /(\mathrm{df})$ & $\mathrm{p}$ \\
\hline Reside $^{\mathrm{b}}$ & & $-2.40(72)$ & $.019^{*}$ \\
Yes & $16.87(1.56)$ & & \\
No & $16.15(1.03)$ & & .20 \\
\hline Married $^{\mathrm{b}}$ & & & \\
Yes & $16.85(1.67)$ & & \\
No & $16.42(1.21)$ & & \\
\hline
\end{tabular}

Note. Quality of life was measured using the Quality of Life Index; ${ }^{a} \mathrm{~N}=75{ }^{b}$ Residence and marital status measured using the Caregiver Demographic Data Form; *p-value significant at .05 level.

Table 4-7. Correlations: QoL and Depressive Symptoms, Family Health/Happiness, and Stress. ${ }^{a}$

\begin{tabular}{lccc}
\hline \multicolumn{1}{c}{ Variable } & $\begin{array}{c}\text { Quality of } \\
\text { Life }\end{array}$ & $\begin{array}{c}\text { Depressive } \\
\text { Symptoms }\end{array}$ & $\begin{array}{c}\text { Family } \\
\text { APGAR }\end{array}$ \\
\hline Quality of life $^{\mathrm{b}}$ & - & & \\
Depressive symptoms $^{\mathrm{c}}$ & -.22 & & \\
Family Health/Happiness $^{\mathrm{d}}$ & $.29^{*}$ & -.46 & \\
Stress $^{\mathrm{e}}$ & $-.35^{*}$ & .45 & -.48 \\
\hline
\end{tabular}

Note. ${ }^{\mathrm{a}} \mathrm{N}=75$; ${ }^{b}$ Quality of Life Index measured quality of life; ${ }^{\mathrm{c}} \mathrm{CES}-\mathrm{D}$ measured depressive symptoms; ${ }^{\mathrm{d}}$ Family APGAR measured family functioning; In the current study family health/happiness was operationalized as family functioning; ${ }^{\mathrm{e}}$ Burden Interview measures caregiver burden; In the current study stress was operationalized as caregiver burden; In the current study happiness was operationalized as absence of depression; *p-value significant at .05 level. Pearsons' $r$ was used to calculate the correlation coefficient. 
Table 4-8. Dummy Codes of Categorical String Variables.

\begin{tabular}{lc}
\hline \multicolumn{1}{c}{ Categorical Variable } & Dummy Codes \\
\hline Married & 0 \\
$\quad$ No & 1 \\
Yes & \\
& \\
Full-time Employment & 0 \\
$\quad$ No & 1 \\
Yes & \\
Part-time Employment & \\
$\quad$ No & 0 \\
Yes & 1 \\
\hline
\end{tabular}

$0=$ absence of characteristic; $1=$ presences of characteristic

Table 4-9. Predictors of Quality of Life. ${ }^{\mathrm{a}}$

\begin{tabular}{|c|c|c|c|c|c|}
\hline \multirow[b]{2}{*}{ Predictors } & \multicolumn{2}{|c|}{$\begin{array}{l}\text { Unstandardized } \\
\text { Coefficients } \\
\end{array}$} & \multirow{2}{*}{$\begin{array}{c}\text { Standardized } \\
\text { Coefficients } \\
\text { Beta }\end{array}$} & \multirow[b]{2}{*}{$\mathrm{t}$} & \multirow[b]{2}{*}{$\mathrm{p}$} \\
\hline & B & Std. Error & & & \\
\hline (Constant) & 18.26 & 0.93 & & 19.58 & $<0.0001$ \\
\hline Caregiver Age & 0.01 & 0.01 & 0.07 & 0.84 & 0.402 \\
\hline Marital Status ${ }^{\mathrm{b}}$ & 0.45 & 0.24 & 0.16 & 1.92 & 0.060 \\
\hline Caregiver Education $^{\mathrm{c}}$ & -0.08 & 0.04 & -0.14 & -1.89 & 0.063 \\
\hline Full-time Employment & -1.88 & 0.24 & -0.66 & -7.78 & $<0.0001$ \\
\hline Part-time Employment & -1.66 & 0.32 & -0.42 & -5.26 & $<0.0001$ \\
\hline Stress & -0.03 & 0.01 & -0.30 & -3.29 & 0.002 \\
\hline Depressive Symptoms & -0.01 & 0.01 & -0.01 & -0.05 & 0.963 \\
\hline Family Health/Happiness & 0.03 & 0.02 & 0.10 & 1.06 & 0.291 \\
\hline
\end{tabular}


Table 4-10. Predictors of Quality of Life. ${ }^{a}$

\begin{tabular}{|c|c|c|c|c|c|}
\hline \multirow[b]{2}{*}{ Predictors } & \multicolumn{2}{|c|}{$\begin{array}{l}\text { Unstandardized } \\
\text { Coefficients }\end{array}$} & \multicolumn{2}{|c|}{$\begin{array}{c}\text { Standardized } \\
\text { Coefficients }\end{array}$} & \multirow[b]{2}{*}{$\mathrm{p}$} \\
\hline & B & $\begin{array}{l}\text { Std. } \\
\text { Error }\end{array}$ & Beta & $\mathrm{t}$ & \\
\hline (Constant) & 9.22 & 0.55 & & 34.76 & $<0.0001$ \\
\hline Marital Status & 0.58 & 0.21 & 0.20 & 2.77 & 0.007 \\
\hline $\begin{array}{l}\text { Caregiver } \\
\text { Education }^{\mathrm{c}}\end{array}$ & .0 .09 & 0.04 & -0.16 & -2.18 & 0.033 \\
\hline $\begin{array}{l}\text { Full-time } \\
\text { Employment }\end{array}$ & $\cdot 1.91$ & 0.23 & -0.67 & -8.47 & $<0.0001$ \\
\hline $\begin{array}{l}\text { Part-time } \\
\text { Employment }\end{array}$ & $\cdot 1.72$ & 0.31 & -0.43 & -5.54 & $<0.0001$ \\
\hline Stress & .0 .04 & 0.01 & -0.36 & -4.90 & $<0.0001$ \\
\hline
\end{tabular}

Note. ${ }^{\mathrm{a}} \mathrm{N}=75$, results from backward elimination stepwise regression; Dependent variable: Quality of Life; ${ }^{\mathrm{b}}$ Marital Status denotes Married Caregivers; ${ }^{\mathrm{c}}$ Caregiver

Education measured in years of education. Model Statistics: $R^{2}=0.65, \mathrm{Adj} \mathrm{R}^{2}=0.63$ $(\mathrm{F}=19.26, \mathrm{p}<0.0001)$. 


\section{Discussion}

We conducted a secondary data analysis of predictors of QoL among African American women who were caregivers of persons with ESRD on dialysis using variables derived from the elements of Ferrans' Conceptual Model for Quality of Life. To our knowledge, this is the only study in the U.S. that has examined the predictors of overall QoL in African American women caregivers in the context of ESRD. Few studies have considered the experiences of these family caregivers despite the higher incidence of ESRD in African Americans. The current study differs from other caregiving studies because we used a QoL framework while other studies have used stress and coping frameworks (Clay et al., 2013; Dilworth-Anderson, Goodwin, \& Williams, 2004; Wicks et al., 1998). In this study, African American women rated their QoL favorably. These results differ slightly with prior studies that reported high QoL in caregivers of persons with ESRD and lung transplant candidates (Lefaiver et al., 2009; Meecharoen et al., 2013; Wicks et al., 1998). Many factors such as hours worked, age, educational level, satisfaction with support received, residency status and satisfaction with family health/happiness were significantly associated with caregivers' QoL. Employment status, education, and stress had the largest effect on the caregivers' QoL. These findings suggest many facets of caregivers' lives can affect their QoL. Clinical practice guidelines, health policies, and theories should be developed or implemented to address areas of significance because they have an impact on the QoL of African American women who are caregivers.

\section{Demographic Findings}

The current study was limited to African American women to address study aims. As it relates to gender, there are socially constructed roles, activities, behaviors, and attributes that a given society considers appropriate for men and women. Women do more housework than men do in most of the world (WHO, 2011). Stereotypically, women are more emotional and emotionally dependent upon others around them and supposedly find it difficult to distinguish personal well-being from the well-being of their children and partners. The prevalence of informal caregiving is higher among Asians and African Americans (31.7\% and 29.4\%, respectively) than among Hispanics (26.8\%) and Whites (24\%) (Talley \& Crews, 2007). Ethnic minorities are more likely to provide informal caregiving than Whites because of cultural preferences for informal care, concern regarding substandard care in informal settings, lack of access to proper care due to inadequate finances, and unequal access to care (Picot, \& Hill-Westmoreland, 2002). The demands of caregiving leave little time for the caregiver to tend to their needs (Wicks et al., 2007).

Most caregivers in the current study were about 47 years old. This finding is consistent with a national survey of caregivers (National Alliance for Caregiving and AARP Public Policy Institute, 2015). Though the effect size was small, age was positively correlated with QoL. In other studies, young caregivers experienced better QoL than older aged caregivers (Chou, Lee Y.C., Lin, Kroger, \& Chang, 2009). The QoL 
in the current study was similar for single (38\%) and married (41\%) caregivers. Also, most of the caregivers $(63 \%)$ in the study lived with the recipient. The majority of the study's caregivers had some high school education (49\%) and college education (48\%). Many of the caregivers (44\%) were employed full-time. In the current study, income was excluded because ( 20 caregivers) failed to report income. Similar to a national study, the caregivers in the current study provided about 27 hours of care per week and cared for the recipient for about five years (National Alliance for Caregiving and AARP Public Policy Institute, 2015). A demographic variable in the original study, caregivers' satisfaction with support, and the support they received from others was rated as satisfactory (45\%). Many studies of caregivers show that they are married women, a parent, or a sibling (Flynn-Longmire \& Knight, 2011; Teschendorf et al., 2007). Caregivers of persons with chronic illnesses have varying levels of QoL that are affected by multiple factors in their life. The goal of this study was to determine the predictors of QoL in African American women caring for persons with ESRD.

Study aim one was to describe the association between demographic factors, such as age and socioeconomic status (SES) and overall QoL. The results revealed that caregivers who worked more hours reported worse QoL. This may be due to problems with flexible work schedules. It is likely that caregivers have difficulty adjusting their schedules to help care recipients with their needs. The inverse relationship between SES and QoL may also occur if caregivers need more income to take care of the recipient. These caregivers may work more, but still experience financial burden. Collins and Swartz (2011) reported that caregivers have an annual income of less than 50 thousand dollars, and spend over five thousand dollars yearly caring for the recipient. Additionally, older age and providing more hours of weekly care was positively associated with QoL scores. Past research has shown that patient characteristics (i.e., age and marital status) are associated with caregivers' QoL (Aguilar et al., 2006). Caregivers are a valuable resource for national healthcare, but their health often declines from neglect associated with difficulty managing disruptive schedules (Smith, Piamjariyakul et al., 2010). Caregivers experience loss of personal time/pleasure and deprivation of time. Some caregivers cancel time for personal functions to make time for caregiving. The lack of leisure time may generate a loss of joy and restricted freedom. Caregivers resist the need to put their needs first so they can care for the recipient (Teschendorf et al., 2007).

Ethnic minority groups, such as African American and Hispanics are more likely to reside with the recipient. Caregivers who reside with the recipient spend more time providing care weekly and assisting with activities of daily living activities of daily living (i.e., personal care, in and out of bed and chair transfers) (Weiss, Gonzalez, Kabeto, \& Langa, 2005).

Study aim two was to describe the relationship between caregiver stress and QoL. Caregiver burden has similarly been referred to as caregiver stress and strain in the literature. Most of the caregivers in the current study $(67 \%, \mathrm{n}=50)$ reported little to no stress. In the present study, stress and QoL was inversely related. Though this finding was significant, the effect size was small $(\mathrm{r}=-.35)$. The before mentioned findings are similar to a study by Zauszniewski, Picot, Roberts, Debanne, and Wykle (2005) who 
reported that African American women taking care of elderly persons reported poor QoL when they experienced more perceived burden and strain. Likewise, M. H. Bellin et al. (2015) found an inverse relationship between stress and QoL of African American mothers of children with poorly controlled asthma. Furthermore, African American women who are caregivers and report little stress experienced better QoL than those who reported high levels of stress (Scharlach et al., 2006; Stevens, 2014); Zauszniewski et al. (2009) found that African American women with higher perceived stress experienced low QoL. This finding of low stress levels was expected since African Americans tend to find caregiving less burdensome and more rewarding than other ethnic groups - albeit a difficult task. It is thought to be rewarding to caregivers because of their emotional closeness to recipients and their opportunity to show reciprocity in the relationship. Caregiving helps some discover new meaning in life, personal growth, and see it as a special opportunity (Teschendorf et al., 2007). The caregiving role can also result in positive experiences. Some experiences have been reported as rewarding because caregiving fosters the development of closer relationships with the patients, and helps one discover inner strength. Caregiving can also helps the caregiver gain a new or different life perspective (Williams et al., 2009; Rodrigue et al., 2010).

Moreover, ethnicity can influence perceptions of stress in many ways and for reasons such as caregiver characteristics, family structure, and differences in coping (Pinquart \& Sorensen, 2005). African Americans tend to respond to stress differently than Whites, Asians, and Hispanics (Covinsky et al., 2003). African Americans' use of spirituality and religion for coping has been thought to significantly lower stress (Pinquart \& Sorensen, 2005; Spurlock, 2005). Asian Americans' perception of stress tends to be related to unsatisfactory family functioning and lack of social support and older age, (Chien, Chan, \& Morrissey, 2007). There is a societal and cultural expectation that African American women manifest strength for the sake of their families and friends even when the responsibility is not voluntary. Historical legacies of strong African American women, ancestral teachings, and spiritual values may cause African American woman to feel obligated and privileged to have their family dependent upon them (Woods-Giscombe, 2010). It is not uncommon for women from ethnic minority groups to put their needs and desires on hold to meet the needs of others (Meecharoen et al., 2013). Other African American caregivers feel that they are able to handle any difficult task because God "doesn't put more on them than they can bear."

The present study reveals that African American women who care for family members report favorable QoL; however, the expectation and obligation to provide care may be a significant factor because high demands are often placed on African American women. African American women often overcommit to tasks given by others and feel guilty or have difficulty declining assigned responsibility (Woods-Giscombe, 2010). In meeting assigned responsibilities, African American women are at an increased exposure to stressors that require sustained high levels of coping which results in wear and tear on biological systems (Geronimus, Hicken, Keene, \& Bound, 2006). African American women's reaction to stressful life events may affect their psychological health, and their physical health (Black, Murry, Cutrona, \& Chen, 2009). This high level of sustained 
coping that caregiving brings may contribute to high mortality and morbidity rates in African American women in the U.S. (Office of Women's Health, 2012).

Study aim three was to describe the association between depressive symptoms and overall QoL. The depressive symptom scores for over half $(59 \%, n=44)$ of the caregivers were greater or equal to the cutoff for persons at risk for mild clinical depression (16.0). In the current study, caregiver depressive symptoms scores and QoL were inversely related. However, this finding was not statistically significant. The depressive symptom score in caregivers in the present study was a surprising and unexpected result since depressive symptoms are not commonly reported among African Americans. Additionally, depression and depressive symptoms scales are more likely to identify depression in Whites than blacks and show more concordance with Whites than Blacks. Further, African Americans tend to deny depression in self-report measures, but report depression more often when interview measures, such as the Hamilton Rating Scale for Depression (HAM-D) are used (Zhang \& Gary, 2013).

The high depressive symptoms score did not seem to affect the QoL of the caregivers like some studies in which psychological health was predictive of QoL (Wadhwa et al., 2013). Family satisfaction and low reported stress levels may have buffered the effects of the high levels of depressive symptoms on QoL in African American women caring for persons with chronic illnesses resulting in a sample of caregivers who experienced moderate QoL. Blacks report fewer depressive symptoms than whites when living apart from the care recipient, but experience higher rates of depressive symptoms when living with the care recipient (Flynn-Longmire \& Knight, 2011; Siegler et al., 2010). Many of the caregivers lived with the recipient in the present study, which may explain why the caregivers in the current study experienced high depressive symptom scores. Some family members who are caregivers experience depression, especially if they provide care for many hours throughout the day. Caregiver depression can cause neglect, early institutionalization, and elder abuse of the carerecipient (Ladner \& Cuellar, 2003). Women may have unique risk factors for depression such as an obligation to care for others, income inequality, and socioeconomic disadvantage. Caregiving adds risk factors for depression in women. Women provide a majority of long-term care for ill family members, friends, and community and often have higher levels of depression (American Psychiatric Association, 2009).

Study aim four was to describe the association between family health and happiness and overall QoL. Most caregivers (63\%) in the current study were always satisfied with family health/happiness. In the current study, caregivers who reported higher satisfaction with family health/happiness also reported higher QoL. The findings in the current study were statistically significant though the effect size was small $(\mathrm{r}=.29)$. Nonetheless, these findings are consistent with other studies. African American families tend to spend more time together and have a strong commitment to familial responsibilities compared to Caucasians (Mouzan, 2013; Pickard et al., 2004). Ethnic minority groups tend to have extended families as a result of migratory patterns and customary traditions of caring for one another as a result of migration and cultural survival from incidents such as oppression, slavery, racism, and poverty. Additionally, 
ethnic minorities depend on their family because of traditional values that encourage reciprocity and interdependence on family for providing care to more elderly or dependent family members (Becker, Beyene, Newsom, \& Mayen, 2003). Latinos, Asian American, and African American groups place a higher value on extended family networks than White ethnic groups and have filial beliefs that deter the use of informal institutions. These ethnic minority groups tend to accept responsibility for taking care of family members and extended families instead of placing them in informal caregiving institutions (Covinsky et al., 2003; Napoles, Chadiha, Eversley, \& Moreno-John, 2010; Weiss et al., 2005).

Study aim five was to describe the extent to which demographic factors (i.e., marital status, education, employment status, age), stress, happiness, and family health and happiness predict QoL. The strongest predictors of QoL in the current study were caregivers' full-time employment status $(\beta=-.67, \mathrm{p}<0.0001)$, caregivers' part-time employment status $(\beta=-.43, \mathrm{p}<0.0001)$, and caregiver stress $(\beta=-.36, \mathrm{p}<0.0001)$.

African American women who were caregivers and worked full-time experienced poorer QoL than African American woman caregivers who were retired, unemployed, homemakers, or employed part-time. It is reasonable that women who work full-time experience poorer QoL. African American women often have more responsibility for the economic and social survival of their families. Women often do not negate caregiving responsibilities because of work obligations. Additionally, women may have more financial difficulty than men when they are caring for a family member with a chronic illness with evidence that they miss work twice as much as men (Robison et al., 2009).

African American women who are caregivers earn about \$37,000 yearly and provide an average of 27 hours weekly. The annual average earnings of African American women is below the median average of caregivers of all backgrounds; however, a recent national survey revealed that African American woman experienced little to no financial strain (National Alliance for Caregiving \& AARP Public Policy Institute, 2015). In the current study, income was excluded because a majority of the sample did not report income. Nonetheless, there are financial challenges for women who work and provide care to persons with chronic illnesses. Additionally, caregiving comes with many financial challenges for women who work but provide care to persons with chronic diseases. For example, lost wages from time off and reduced work hours can be a challenge. Even though women comprise almost half of the workforce in the U.S. and are the primary breadwinners, women earn less income annually than men (Family Caregiver Alliance: National Center on Caregiving, 2015; The Council of Economic Advisors: Executive Office of the President of the United States, 2014). Caregiving may involve daily work interruptions as women often leave work early, come to work late, or take extended breaks to manage the recipients' care (Family Caregiver Alliance: National Center on Caregiving, 2015). Despite being primary caregivers, African American women are more likely to work in lower paid occupations than women from other racial and ethnic backgrounds and White men (U.S. Bureau of Labor Statistic, 2016). Caregivers who provide greater than 21 hours of care and reside with the care recipient often need to make work accommodations (Feinburg \& Choula, 2012). In the current 
study, caregivers provided an average of 27 hours of care weekly, and $63 \%(n=47)$ lived with the care recipient. Caregivers from minority and low-income groups are likely to decrease work hours and leave work because of caregiving responsibilities. Not only may African American woman earn less, but they may also have limited retirement benefits (Feinburg \& Choula, 2012).

People of color are more likely than Whites to experience economic difficulty during retirement for other reasons such as differences in education, job segregation, poverty, and higher mortality and morbidity (Center for Community Change \& Older Women's Economic Security Task Force, 2013). Women who are caregivers tend to outlive men but have less access to retirement savings and pensions (Family Caregiver Alliance: National Center on Caregiving, 2015). Mellon et al. (2006) and Roth et al. (2009) found that individuals who were retired caregivers often experience better QoL than employed caregivers or caregivers who were homemakers. Social security benefits, retirement funds, and health insurance are affected by a decrease in work hours. Social security income for women over the age of 65 was $\$ 5000$ less than social security income for men in 2013 (Center for Community Change \& Older Women's Economic Security Task Force, 2013). Women over age 50 lose twice as much as men when they leave work to care for a parent (Feinburg \& Choula, 2012).

Many of the women in the current study may be at risk for poverty as Feinburg and Choula (2012) reported that assuming the caregiving role increased women's risk of living in poverty in old age. Women of color have greater risks for poverty because of the likelihood of having worked in low wage or part-time positions (Center for Community Change \& Older Women's Economic Security Task Force, 2013). Caregiving can be an added expense since some caregivers may have to pay for medications and other supplies that the care recipient may need.

African American women who cared for a person other than a family member (i.e., husband, child, parent, sibling) in the current study experienced the lowest QoL scores. Many African American caregivers often provide assistance to persons such as friends or persons with no familial relationship (also known as fictive kin) in contrast to Whites who care mostly for parents (Drentea \& Goldner, 2006). Caregiving is often viewed as a ministry in the African American community, so it is not uncommon for an individual to provide assistance to someone with no familial ties. In a qualitative study of African American caregivers, some caregivers referenced that being Christian meant to help anyone in need (Bennett, Sheridan, \& Richardson, 2014). Also, many African American caregivers provide assistance to other persons, such as grandchildren, children, and other family members (i.e., aunts, uncles, cousins) in addition to caregiving duties for a chronically ill person (Hargrave, 2010). Nonetheless, Mellon et al. (2006) found that most family caregivers were either adult children or spouse. Spouses who are caregivers generally have higher QoL than adult children caregivers (Mellon et al., 2006). The current study has similar findings with most of the African American women caregivers being adult children or spouses, in which the wives experienced higher QoL than African American women who were caring for a parent. It is plausible that African American women caregivers who were related to the recipient experience better QoL than those 
who are not related. Caregiving may bring the recipient and caregiver's relationship closer. To add, the role of caregiving can be rewarding because it fosters the development of closer relationships with the recipient, helps one discover inner strength, shows love and appreciation, and helps one gain new and varying perspectives on life (Hargrave, 2010; Rodrigue et al., 2010).

The current study was important because it examined predictors of overall QoL of African American woman caregivers of persons with ESRD. Many other studies of caregivers examine only the physical and psychological aspects of one's QoL that do not completely describe caregivers' life circumstances that may impact their QoL.

The findings in the current study add to the current body of knowledge about QoL in African American women caring for persons with a chronic illness. First, a multidimensional subjective measure of QoL was used in contrast with many other studies that use HRQoL measures which examine only psychological and physical well-being. Examining only psychological and physical factors in the lives of caregivers excludes other facets of life that may affect QoL. It is important for health care providers to understand that people are multi-dimensional; thus, using measures that only address psychological and physical factors may omit important areas of life that could significantly affect QoL. It is important to consider the totality of one's life when assessing QoL as many things can predict and protect it. We also extended current knowledge in the current study by using a QoL framework.

\section{Implications for Practice and Future Studies}

\section{Policy Implications}

The average time for treatment discoveries to translate from bench to bedside is 17 years (Agency for Healthcare Research and Quality; Finkelman \& Kenner, 2010; Institute of Medicine (US) Committee on the Health Professions Education Summit, 2003; Obama, 2009). Researchers must be knowledgeable of obstacles that impede utilization of findings to overcome barriers to the transition of research from bench to bedside. Policy-making is a crucial activity in research; thus, it should be considered when planning approaches to translate findings. The timing of the study is important because older people are presently working longer and are providing care to older, and chronically ill people. Many employers lack sound policies for these working caregivers. Caregivers' work provides the country with an extraordinary service that keeps individuals with chronic illnesses out of institutions. Caregiving saves the U.S. about $\$ 100$ billion annually (Gonzales, Lee, Brown, \& Goettge, 2015). Because caregivers experience difficulty with retirement benefits or are forced to retire early, employers could give caregivers credit if an economic value were given to caregiving.

For this reason, supportive policies should be in place to assist these caregivers. Companies can implement three existing national policies and recommendations to 
support working caregivers: The Association for the Advancement of Retired Persons (AARP), Respect a Caregivers Time (ReAct), the Equal Employment Opportunity Commission (EEOC), and the Alzheimer's Workplace Alliance group initiatives (AWA). The AARP ReAct program adopted a "best practice" approach to maintaining workers who may experience problems with work as a result of caregiving. The AARP ReAct policy suggests interventions such as educating employees about the process of caregiving and ways the program can help them in their dual role as worker and caregiver.

The EEOC suggest that flexible workplace policies help caregivers experience better work life balance and better QoL. Flexible workplace policies reduce absenteeism, cost, and enhance employee productivity. These policies also help with retention and recruitment efforts, allowing employers to keep trained workers, and save the time or money that would otherwise have been spent searching for new employees. Some suggestions include proper training of management with emphasis on adhering to policies that protect caregivers. The EEOC also encourages employers to focus on individuals' qualification - not caregiving responsibilities, target positions directed at caregivers, and identification and removal of barriers to re-entry after leaves of absences. Lastly, the policy suggests to monitor performance appraisals, encourage employees to arrange flexible working schedules, post schedules early, provide reasonable and flexible sick time, and reassign job duties caregiving employees are unable to perform (The U.S. Equal Employment Opportunity Commission, 2011). The AWA provides assistance to its members to help their employees balance caregiving responsibilities and employment by providing information, tools, and resources on Alzheimer's disease. This support for employers could be applied to caregivers of persons with other chronic conditions (Alzheimer's Association, 2015). Not only does caregiving affect caregivers who work, but also employers. Businesses in the U.S. lose about $\$ 33$ billion yearly in productivity from losing full-time caregivers from costs associated with replacing workers, caregivers being absent from work or reducing hours. Employers also have higher health care costs for caregivers than non-caregivers because caregivers are likely to have poorer health than the latter (Feinburg \& Choula, 2012).

\section{Practice Implications}

Quality of life can be assessed in caregivers by HCPs. This may help HCPs make appropriate decisions in care and measure changes over time (World Health Organization, 2012). During any healthcare encounter, health care providers should assess individuals' caregiver and employment statuses. Assessment of caregiver status may be necessary especially when individuals come in for problems such as stress and depression. A work-life balance assessment may be helpful to assess for work-related stressors and responsibilities in caregivers. Health care providers should become familiar with and establish a referral network with community organizations or other helpful resources to provide caregivers with the assistance they need. Health care providers could also examine stressors related to caregiving, work, and living situations (i.e., other children in the home). The before mentioned factors are important and may be quickly 
assessed during patient encounters. Health care providers caring for African American woman who are caregivers should evaluate for signs and symptoms of stress and employment status. Thus, interventions could focus on using appropriate but succinct screenings in the primary care setting when African American woman present with somatic symptoms. Proper identification and treatment of psychological issues may improve the QoL, overall physical health, and decrease health disparities in African American woman. Nephrology nurses and social workers should develop a referral network with primary care physicians. The referral network could be used when caregivers at risk for poor QoL are identified. Collins and Swartz (2011) offer important recommendations for practice that nephrology social workers and nurses can implement such as offering caregiver assessments to identify burden and QoL in caregivers, encourage caregivers to take care of themselves (i.e., maintain a healthy diet, seek preventive care, join support group), and provide necessary education and resources. Skills training, psycho-education and therapeutic counseling are recommended, but have small to moderate success in improving QoL and decreasing burden.

Specifically, Collins and Swartz (2011) offer guidelines which HCPs can implement to assess caregivers. The QoL model used in this study address those areas (Ferrans, 1996). Further assessment of caregivers' needs could be used as the basis for formulating care plans to identify appropriate resources.

\section{Theoretical Implications}

The findings in the current study have limited theoretical implications. The model used in the current study was developed using qualitative and quantitative methods in a group of middle-class-White men on hemodialysis and examined factors they found essential to life. A QoL model that explores the intersections of race/culture, class, and gender in addition to other domains of this model would likely be more culturally appropriate. Nonetheless, the model was comprehensive in covering many aspects of one's life that could be affected which lead to the investigation of health/functioning, psychological/spiritual, social/economic, and family domains which other QoL models do not commonly address.

\section{Limitations and Strengths}

This study has several limitations. First, this study was a secondary data analysis from a larger study. A major disadvantage of secondary data analysis is investigator lack of control over the data collection. The sample, quantity and quality of data, operational and theoretical definitions, and conceptual framework are all predetermined and collected for other purposes; therefore, the data will not address new research questions (Boslaugh, 2007; Coyer \& Gallo, 2005; Doolan \& Froelecher, 2009; Hulley, Cummings, Browner, Grady, \& Newman, 2007 ; Nicoll \& Beyea, 1999). With more control over the current study, we could have assessed caregivers' coping strategies, or investigated the variable of support further. Aside from methodological issues, other disadvantages of using 
secondary data sources are ethical issues, potentially biased data, and missing or outdated data (Coyer \& Gallo, 2005; Doolan \& Froelecher, 2009; Schwartz \& Panacek, 1996). Many researchers assume that using secondary data always saves time, but contrarily, it may extend research time. This extension in time is possible because the researcher must learn and understand the previous researcher's variables and methods (Windle, 2010). Despite this limitation, findings from the present study have merit and are supported by the research studies that are mentioned in the discussion of the results.

Secondly, the study used a descriptive, predictive, correlational design, which is used when data are gathered at one point in time. For this reason, the results do not reflect caregivers' QoL over time. A longitudinal research study would be useful to examine significant predictors of QoL over time in African American woman who care for persons with ESRD. However, the descriptive, predictive, correlational design was consistent with the purposes of the study. The purpose of this study was to describe factors that contribute to and predict QoL for African American woman who care for persons with ESRD.

Thirdly, interpretation of the study findings is limited because the sample was restricted to African American women. Additionally, the study was restricted to participants in the Southeastern metropolitan area, which may affect the generalizability of the findings. Next, the QoL measure used in this study may make comparisons across studies difficult. Even though QoL research has been receiving attention in recent research, the definition is inconsistent across studies (Chien et al., 2003). Studies often report outcomes as QoL, when they measure HRQoL or burden. Furthermore, few questionnaires are designed and validated for caregivers (Fan et al., 2006). Valid and reliable caregiver specific QoL instruments are available for chronic illnesses such as Alzheimer's disease, and cancer; development of these tools has proven to be an important step to examine caregiver's QoL (Edwards \& Ung, 2002) .

Several strengths of the study exist though there are several limitations. As it relates to the design of the study, use of secondary data analysis compliments larger studies, helps identify new topics, and decreases harm to participants (Boslaugh, 2007; Coyer \& Gallo, 2005; Doolan \& Froelecher, 2009; Hulley et al., 2007; Nicoll \& Beyea, 1999). A second strength is that the study only included African American woman who were caregivers of persons with ESRD. Even though many caregivers are African American woman, there is a dearth of studies that include African American woman caregivers and study their overall QoL, especially in the context of ESRD. A fifth strength is the examination of overall QoL. Many studies examine HRQoL that gives us information about the physical and psychological well-being of individuals and negates other factors (i.e., social and economic, family) that affect people. Examining overall QoL gives a more subjective and holistic view of the well-being of individuals. A final strength of the study is the use of multiple regression analysis. Multiple regression analyses allow the use of data from various levels of measurement, and are powerful in predicting outcomes, and explaining relationships between variables. 
In summary, caregivers are a diverse group of individuals with different experiences in caregiving. Ethnicity influences caregiving and QoL. It is important to identify these differences in caregivers for interventions to be tailored to suit this population.

\section{Future Research}

The study has generated five recommendations for future research. The first recommendation for future research is to do a qualitative study to understand experiences of working while caregiving in African American women who are caregivers. In the present study, African American women's education and employment status was inversely related to unfavorable QoL scores. An in-depth investigation is needed to understand this inverse association between QoL and education/employment.

A second recommendation is to do a qualitative study to understand the meaningfulness of relationships (i.e., marriage) in African American woman who are caregivers. Many African American women are not married; however, the lack of legal marriage does not denote a lack of companionship. Thus, differences in relationships and family structure warrant further examination.

A third recommendation is to do a mixed methods study to examine stress with the use of quantitative, qualitative, and biological measures of stress (i.e., salivary cortisol levels, hyperlipidemia, waist to hip ratio, heart rate variability) in African American women who are caregivers of persons with chronic illnesses. The reason this type of study may be useful is that studies consistently report little to no burden, but high cardiovascular risks in African American women who are caregivers. The consistent findings of little to no burden are surprising considering factors such as poorer health status and lower SES of African American women. The leading three causes of mortality among black women in the U.S. include heart disease, cancer, and stroke. To add, African American women, age 20-39, have the highest obesity rates in the U.S. (Centers for Disease Control, 2010; Centers for Disease Control and Prevention, 2013; Jackson et al., 2010). Researchers have reported that obesity has a link to stress and hypothalamuspituitary dysfunction. Chronic stress is associated with the propensity to consume foods that are nutritionally sparse (i.e., high simple carbohydrates and fat) and other negative health behaviors such as smoking (Jackson et al., 2010; Torres \& Nowson, 2007). Not only do behavioral risk factors influence the development of heart disease and stroke, but also affect the development of mental health issues such as depression, anxiety, and stress (Douglass \& Poppas, 2013; Furie \& Rost, 2013). The before mentioned mental health problems left undetected may silently and negatively affect the QoL in African American women who are caregivers. Stress significantly affects the QoL of caregivers of other ethnicities; thus, further investigation into the mutual exclusiveness of stress in African American woman is warranted.

The fourth recommendation for future studies is to assess clinicians' knowledge of the resources to assist patients that may be receiving care. Clinicians should not only 
identify caregivers, at all health care encounters but also be equipped to intervene on identified problems. Clinicians may not be prepared to help caregivers if they have limited access or knowledge to available and necessary resources. More work is needed to integrate practices and resources that improve outcomes for caregivers.

A final recommendation to further understand the experiences of African American woman who are caregivers is to use the most culturally relevant assessment measures, theoretical frameworks, and methodologies. A recommended theoretical framework and strategy is intersectional research. This type of analysis starts with the experiences of marginalized groups (i.e., African American women) and examines the interconnected structures of power that affect their identities and choices. This approach may promote health equities that may promote high QoL. Intersectionality as a framework may offer strength to health inequities. This framework may generate knowledge to help healthcare providers understand health disparities and QoL for historically marginalized populations (i.e., African American woman). The framework may also illustrate how systems of advantage and oppression intersect at the macro-social structural level to reinforce and maintain health inequities that may result in poor QoL for individuals. Focus on social structural factors allows deeper examination on how resources and social systems support health inequalities; thus poor QoL. This paradigm moves away from interventions that focus on single or individual level factors.

\section{Conclusion}

Caring for persons with ESRD potentially affects caregivers' QoL because the condition is complicated to manage and may cause significant life changes for the caregiver. This study identified predictors of QoL in African American women who care for individuals with ESRD. Education and employment status, marital status, and stress were found to be the most influential factors that predicted QoL of African American women in this study. The results of this study may be a supporting body of knowledge for future studies to investigate and develop interventions that address and improve the most significant areas of life that affect the overall QoL in African American women who provide care to persons with ESRD. 


\section{LIST OF REFERENCES}

Agency for Healthcare Research and Quality. Translating research into practice (TRIP)II. Retrieved from http://www.ahrq.gov/research/findings/factsheets/translating/tripfac/index.html

Aggar, C., Ronaldson, S., \& Cameron, I. D. (2011). Self-esteem in carers of frail older people: Resentment predicts anxiety and depression. Aging \& Mental Health, 15(6), 671-678. doi:10.1080/13607863.2011.562176

Alzheimer's Association. (2015). Alzheimer's Workplace Alliance. Retrieved from http://www.alz.org/awa/join.asp

American Psychiatric Association. (2009). Women's mental health: Issue paper 2009. Retrieved from http://www.psych.org/share/OMNA/Womens-Mental-HealthIssue-Paper.aspx

American Psychological Association. (2015). Fact sheet: Women and socioeconomic status. Retrieved from http://www.apa.org/pi/ses/resources/publications/factsheet-women.aspx

American Psychological Association. (2016a). Ethnic and racial minorities and socioeconomic status. Retrieved from http://www.apa.org/pi/ses/resources/publications/factsheet-erm.aspx

American Psychological Association. (2016b). Positive aspects of caregiving. Retrieved from http://www.apa.org/pi/about/publications/caregivers/faq/positiveaspects.aspx

Anaforoglu, I., Ramazanogullari, I., Algun, E., \& Kutanis, R. (2012). Depression, anxiety and quality of life of family caregivers of patients with type 2 diabetes. Medical Principles and Practice 21(4), 360-365. doi:10.1159/000334622

Anderson, K. L., \& Burckhardt, C. S. (1999). Conceptualization and measurement of quality of life as an outcome variable for health care intervention and research. Journal for Advanced Nursing, 29(2), 298-306.

Anees, M., Hameed, F., Mumtaz, A., Ibrahim, M., \& Saeed Khan, M. N. (2011). Dialysis-related factors affecting quality of life in patients on hemodialysis. Iranian Journal Of Kidney Diseases, 5(1), 9-14.

Bailey, R. K., Blackmon, H. L., \& Stevens, F. L. (2009). Major depressive disorder in the African American population: Meeting the challenges of stigma, misdiagnosis, and treatment disparities. Journal of the National Medical Association, 101(11), 1084-1089. 
Bamm, E. L., \& Rosenbaum, P. (2008). Family-centered theory: Origins, development, barriers, and supports to implementation in rehabilitation medicine. Archives of Physical Medicine and Rehabilitation, 89(8), 1618-1624. doi:10.1016/j.apmr.2007.12.034

Beanlands, H., Horsburgh, M. E., Fox, S., Howe, A., Locking-Cusolito, H., Pare, K., \& Thrasher, C. (2005). Caregiving by family and friends of adults receiving dialysis. Nephrology Nursing Journal, 32(6), 621-631.

Beauboeuf-Lafontant, T. (2008). You have to show strength. Gender and Society, 21(1), 28-51. doi:10.1177/0891243206294108

Becker, G., Beyene, Y., Newsom, E., \& Mayen, N. (2003). Creating continuity through mutual assistance: Intergenerational reciprocity in four ethnic groups. The Journals of Gerontology. Series B, Psychological Sciences and Social Sciences, 58(3), S151-159.

Belasco, A., Barbosa, D., Bettencourt, A. R., Diccini, S., \& Sesso, R. (2006). Quality of life of family caregivers of elderly patients on hemodialysis and peritoneal dialysis. American Journal of Kidney Diseases 48(6), 955-963.

doi:10.1053/j.ajkd.2006.08.017

Belle, S. H., Burgio, L., Burns, R., Coon, D., Czaja, S. J., Gallagher-Thompson, D., . . . Zhang, S. (2006). Enhancing the quality of life of dementia caregivers from different ethnic or racial groups: A randomized, controlled trial. Annals of Internal Medicine, 145(10), 727-738.

Bellin, M. H., Kub, J., Frick, K. D., Bollinger, M. E., Tsoukleris, M., Walker, J., . . Butz, A. M. (2013). Stress and quality of life in caregivers of inner-city minority children with poorly controlled asthma. Journal of Pediatric Health Care, 27(2), $127-134$.

Bellin, M. H., Osteen, P., Kub, J., Bollinger, M. E., Tsoukleris, M., Chaikind, L., \& Butz, A. M. (2015). Stress and quality of life in urban caregivers of children with poorly controlled asthma: A longitudinal analysis. Journal of Pediatric Health Care, 29(6), 536-546. doi:10.1016/j.pedhc.2015.04.018

Bennett, S., Sheridan, M., \& Richardson, F. (2014). Caregiving as ministry: Perceptions of African Americans providing care for elders. Families in Society: The Journal of Contemporary Social Services, 95(1), 51-58.

Berg, J. A., \& Woods, N. F. (2009). Global women's health: A spotlight on caregiving. The Nursing Clinics of North America, 44(3), 375-384. doi:10.1016/j.cnur.2009.06.003

Black, A. R., Murry, V. M., Cutrona, C. E., \& Chen, Y. F. (2009). Multiple roles, multiple lives: The protective effects of role responsibilities on the health 
functioning of African American mothers. Women Health, 49(2-3), 144-163. doi:10.1080/03630240902915051

Black, A. R., \& Peacock, N. (2011). Pleasing the masses: Messages for daily life management in African American women's popular media sources. American Journal of Public health, 101(1), 144-150. doi:10.2105/ajph.2009.167817

Boslaugh, S. (2007). Secondary data sources for public health: A pratical guide. Cambridge, NY: BJC Healthcare.

Byers, D. J., Beard, T. H., \& Wicks, M. N. (2009). African-American women's perceived health status while caring for a relative with end stage renal disease. Nephrology Nursing Journal, 36(6), 599-604, 609-512, 632.

Byers, D. J., Wicks, M., \& Beard, T. (2011). Depressive symptoms and health promotion behaviors of African-American women who are family caregivers of hemodialysis recipients. Nephrology Nursing Journal, 38(5), 425-430.

Byrd, W. M., \& Clayton, L. A. (2001). Race, medicine, and health care in the United States: A historical survey. Journal of the National Medical Association, 93(3 Suppl), 11S-34S.

Canam, C., \& Acorn, S. (1999). Quality of life for family caregivers of people with chronic health problems. Rehabilitation Nursing 24(5), 192-196, 200.

Çelik, G., Annagur, B. B., Yılmaz, M., Demir, T., \& Kara, F. (2012). Are sleep and life quality of family caregivers affected as much as those of hemodialysis patients? General Hospital Psychiatry, 34(5), 518-524.

Center for Community Change \& Older Women's Economic Security Task Force. (2013). Expanding social security benefits for financially vulnerable populations.

Retrieved from http://www.iwpr.org/publications/pubs/expanding-social-securitybenefits-for-financially-vulnerable-populations

Centers for Disease Control. (2015). Health of Black or African American non-Hispanic populations. Retrieved from http://www.cdc.gov/nchs/fastats/black-health.htm

Centers for Disease Control and Prevention. (2009). Healthy aging: Improving and extending quality of life among older Americans. Retrieved from http://www.cdc.gov/nccdphp/publications/aag/pdf/healthy aging.pdf

Centers for Disease Control and Prevention. (2011). Health-related quality of life: HRQOL concepts. Retrieved from http://www.cdc.gov/hrqol/concept.htm

Chien, W. T., Chan, S. W., \& Morrissey, J. (2007). The perceived burden among Chinese family caregivers of people with schizophrenia. Journal of Clinical Nursing, 16(6), 1151-1161. doi:10.1111/j.1365-2702.2007.01501.x 
Chou, Y. C., Lee Y.C., Lin, L. C., Kroger, T., \& Chang, A. N. (2009). Older and younger family caregivers of adults with intellectual disability: Factors associated with future plans. Intellectual and Developmental Disabilities, 47(1934-9491 (Print)), 282-294. doi:10.1352/1934-9556-47.4.282

Clay, O. J., Grant, J. S., Wadley, V. G., Perkins, M. M., Haley, W. E., \& Roth, D. L. (2013). Correlates of health-related quality of life in African American and Caucasian stroke caregivers. Rehabilitation psychology, 58(1), 28. doi: $10.1037 / \mathrm{a} 0031726$

Collins, L. G., \& Swartz, K. (2011). Caregiver care. American Family Physician 1(83), 1309-1317.

Covinsky, K. E., Newcomer, R., Fox, P., Wood, J., Sands, L., Dane, K., \& Yaffe, K. (2003). Patient and caregiver characteristics associated with depression in caregivers of patients with dementia. Journal of General Internal Medicine, 18(12), 1006-1014.

Coyer, S. M., \& Gallo, A. M. (2005). Secondary analysis of data. Journal of Pediatric Health Care 19(1), 60-63. doi:10.1016/j.pedhc.2004.10.003

del Bene, S. B. (2010). African American grandmother raising grandchildren: A phenomenological perspective of marginalized women. Journal of Gerontological Nursing, 36(8), 32-40. doi:10.3928/00989134-20100330-01

Deuster, P. A., Kim-Dorner, S. J., Remaley, A. T., \& Poth, M. (2011). Allostatic load and health status of African Americans and Whites. American Journal of Health Behavior, 35(6), 641-653.

DeVon, H. A., \& Ferrans, C. E. (2003). The psychometric properties of four quality of life instruments used in cardiovascular populations. Journal of Cardiopulmonary Rehabilitation, 23(2), 122-138.

Dilworth-Anderson, P., Goodwin, P. Y., \& Williams, S. W. (2004). Can culture help explain the physical health effects of caregiving over time among African American caregivers? The Journals of Gerontology. Series B, Psychological Sciences and Social Sciences, 59(3), S138-145.

Doolan, D. M., \& Froelecher, E. S. (2009). Using an existing data set to answer new research: A methodological review. Research and Theory for Nursing Practice: An international journal, 23(3), 203-215.

Drentea, P., \& Goldner, M. A. (2006). Caregiving outside of the home: The effects of race on depression. Ethnicity \& Health, 11(1), 41-57. doi:10.1080/13557850500286396 
Edwards, B., \& Ung, L. (2002). Quality of life instruments for caregivers of patients with cancer: A review of their psychometric properties. Cancer Nursing, 25(5), 342349.

Elliott, R. W. (2012). Demographics of the older adult and chronic kidney disease: a literature review. Nephrology Nursing Journal, 39(6), 491-496.

Family Caregiver Alliance: National Center on Caregiving. (2006). Caregiver Health: A population at risk Retrieved from https://www.caregiver.org/caregiver-health

Family Caregiver Alliance: National Center on Caregiving. (2015). Women and cargiving: Facts and figures. Retrieved from http://www.caregiver.org/caregiver/jsp/content node.jsp?nodeid=892

Fan, S. L., Sathick, I., McKitty, K., \& Punzalan, S. (2008). Quality of life of caregivers and patients on peritoneal dialysis. Nephrology, Dialysis, Transplantation, 23(5), 1713-1719. doi:10.1093/ndt/gfm830

Feeley, C. A., Turner-Henson, A., Christian, B. J., Avis, K. T., Heaton, K., Lozano, D., \& $\mathrm{Su}, \mathrm{X}$. (2014). Sleep quality, stress, caregiver burden, and quality of life in maternal caregivers of young children with bronchopulmonary dysplasia. Journal of Pediatric Nursing, 29(1), 29-38. doi:10.1016/j.pedn.2013.08.001

Feinburg, L., \& Choula, R. (2012). Understanding the impact of family caregiving on work Retrieved from http://www.aarp.org/content/dam/aarp/research/public_policy_institute/ltc/2012/u nderstanding-impact-family-caregiving-work-AARP-ppi-ltc.pdf

Ferrans, C. E. (1996). Development of a conceptual model of quality of life. Scholarly Inquiry for Nursing Practice, 10(3), 293-304.

Ferrans, C. E. (2007). Differences in what quality-of-life instruments measure. Journal of the National Cancer Institute Monographs(37), 22-26.

doi:10.1093/jncimonographs/lgm008

Ferrans, C. E., \& Powers, M. J. (1985). Quality of life index: Development and psychometric properties. Advances in Nursing Science, 8(1), 15-24.

Ferrans, C. E., \& Powers, M. J. (1988). Description of the Quality of Life Index Retrieved from https://www.uic.edu/orgs/qli/overview/overviewhome.htm

Ferrans, C. E., Zerwic, J. J., Wilbur, J. E., \& Larson, J. L. (2005). Conceptual model of health-related quality of life. Journal of Nursing Scholarship, 37(4), 336-342.

Finkelman, A., \& Kenner, C. (2010). Professional nursing concepts: Competencies for quality leadership. Sudburry, MA: Jones and Bartlett. 
Flynn-Longmire, C. V., \& Knight, B. G. (2011). Confirmatory factor analysis of a brief version of the Zarit Burden Interview in Black and White dementia caregivers. The Gerontologist, 51(4), 453-462.

Gardner, W., Nutting, P. A., Kelleher, K. J., Werner, J. J., Farley, T., Stewart, L., . . . Orzano, J. (2000). Does the Family APGAR effectively measure family functioning? The Journal of Family Practice, 50, 19-25.

Gayomali, C., Sutherland, S., \& Finkelstein, F. O. (2008). The challenge for the caregiver of the patient with chronic kidney disease. Nephrology, Dialysis, Transplantation, 23(12), 3749-3751. doi:10.1093/ndt/gfn577

Geronimus, A. T., Hicken, M., Keene, D., \& Bound, J. (2006). "Weathering” and age patterns of allostatic load scores among Blacks and Whites in the United States. American Journal of Public Health, 96(5), 826-833. doi:10.2105/AJPH.2004.060749

Gibbins, J., McCoubrie, R., Kendrick, A. H., Senior-Smith, G., Davies, A. N., \& Hanks, G. W. (2009). Sleep-wake disturbances in patients with advanced cancer and their family carers. Journal of Pain and Symptom Management, 38(6), 860-870. doi:10.1016/j.jpainsymman.2009.04.025

Giger, J. N., Appel, S. J., Davidhizar, R., \& Davis, C. (2008). Church and sprituality in the lives of the African American community Journal of Transcultural Nursing, 19(4), 375-383.

Gill, A. S., Singh, A., Matreja, P. S., Gupta, A. K., Singh, N., Khosla, P. P., \& Prasher, P. K. (2011). Assessment of the quality of life of caregiver's of patients suffering from chronic kidney disease. Bantao Journal, 9(1), 31-35.

Gonzales, E., Lee, Y., Brown, C., \& Goettge, K. (2015). Challenges to working longer: Caregiving in later life. Paper presented at the White House Conference on Aging, Boston, MA.

Haley, W. E., Roth, D. L., Hovater, M., \& Clay, O. J. (2015). Long-term impact of stroke on family caregiver well-being: A population-based case-control study.

Neurology, 84(13), 1323-1329. doi:10.1212/WNL.0000000000001418

Hargrave, R. (2006). Caregivers of African-American elderly with dementia: A review and analysis. Annals of Long Term Care, 14(10), 36-40 35p.

Hargrave, R. (2010). Health and healthcare of African American older adults [Press release]. Retrieved from https://geriatrics.stanford.edu/wpcontent/uploads/2014/10/african_american.pdf

Harris, T. T. (2003). Burden and health in caregivers of persons with kidney disease. (Doctoral Dissertation), The University of Tennesee Health Science Center. 
Harris, T. T., Thomas, C. M., Wicks, M. N., Faulkner, M. S., \& Hathaway, D. K. (2000). Subjective burden in young and older African-American caregivers of patients with end stage renal disease awaiting transplant. Nephrology Nursing Journal, 27(4), 383-391.

Hebert, R. S., Weinstein, E., Martire, L. M., \& Schulz, R. (2006). Religion, spirituality and the well-being of informal caregivers: A review, critique, and research prospectus. Aging and Mental Health, 10(5), 497-520.

Heidari Gorji, M. A., Bouzar, Z., Haghshenas, M., Kasaeeyan, A. A., Sadeghi, M. R., \& Ardebil, M. D. (2012). Quality of life and depression in caregivers of patients with breast cancer. BioMed Central Research Notes, 5, 310. doi:10.1186/17560500-5-310

Holt, C. L., Caplan, L., Schulz, E., Blake, V., Southward, P., Buckner, A., \& Lawrence, H. (2009). Role of religion in cancer coping among African Americans: A qualitative examination. Journal of Psychosocial Oncology, 27(2), 248-273.

Houser, A., \& Gibson, M. J. (2008). Valuing the invaluable: The economic value of family caregiving, 2008 update. Retrieved from http://assets.aarp.org/rgcenter/il/i13 caregiving.pdf

Hulley, S. B., Cummings, S. R., Browner, W. S., Grady, D. G., \& Newman, T. B. (2007 ). Designing clinical research. Philadelphia, PA: Lippincott Williams \& Wilkins.

Institute of Medicine (US) Committee on the Health Professions Education Summit. (2003). Health professions education: A bridge to quality. In A. C. G. a. E. Knebe (Series Ed.)

Jackson, J. S., Knight, K. M., \& Rafferty, J. A. (2010). Race and unhealthy behaviors: Chronic stress, the HPA axis, and physical and mental health disparities over the life course. American Journal of Public Health, 100(5), 933-939. doi:10.2105/AJPH.2008.143446

Jones, C., \& Shorter-Gooden, K. (2003). Shifting: The double lives of black women in America. New York, NY: HarperCollins.

Kaufman, A. V., Kosberg, J. I., Leeper, J. D., \& Tang, M. (2010). Social support, caregiver burden, and life satisfaction in a sample of rural African American and White caregivers of older persons with dementia. Journal of Gerontological Social Work, 53(3), 251-269. doi:10.1080/01634370903478989

Kilis-Pstrusinska, K., Medynska, A., Adamczak, P., Balasz-Chmielewska, I., Grenda, R., Kluska-Jozwiak, A., ... Zwolinska, D. (2013). Anxiety in children and adolescents with chronic kidney disease--multicenter national study results. Kidney \& Blood Pressure Research, 37(6), 579-587. doi:10.1159/000355738 
Lefaiver, C. A., Keough, V. A., Letizia, M., \& Lanuza, D. M. (2009). Quality of life in caregivers providing care for lung transplant patients. Progress in Transplantation, 19(2), 142-152.

Leow, M. Q., Chan, M. F., \& Chan, S. W. (2014). Predictors of change in quality of life of family caregivers of patients near the end of life with advanced cancer. Cancer Nursing, 37(5), 391-400. doi:10.1097/NCC.0000000000000101

Lim, J. W., \& Zebrack, B. (2004). Caring for family members with chronic physical illness: A critical review of caregiver literature. Health and Quality of Life Outcomes, 2, 50. doi:10.1186/1477-7525-2-50

Limpanichkul, Y. (2004). Thai caregivers of end stage renal disease patients: Quality of life. (Ph.D.), University of Colorado Health Sciences Center. Available from EBSCOhost ccm database.

Mailoux, L. U., \& Burkart, J. M. (2015). Dialysis modality and patient outcome. Retrieved July 8, 2015, from UpToDate

Makambi, K. H., Williams, C. D., Taylor, T. R., Rosenberg, L., \& Adams-Campbell, L. L. (2009). An assessment of the CES-D scale factor structure in black women: The Black women's health study. Psychiatry Research, 168(2), 163-170. doi:10.1016/j.psychres.2008.04.022

Makkar, V., Kumar, M., Mahajan, R., \& Khaira, N. S. (2015). Comparison of outcomes and quality of life between hemodialysis and peritoneal dialysis patients in Indian ESRD population. Journal of Clinical and Diagnostic Research 9(3), OC28OC31.

McKenna, A. M., Keating, L. E., Vigneux, A., Stevens, S., Williams, A., \& Geary, D. F. (2006). Quality of life in children with chronic kidney disease-patient and caregiver assessments. Nephrology, Dialysis, Transplantation 21(7), 1899-1905. doi:10.1093/ndt/gfl091

Meecharoen, W., Sirapo-ngam, Y., Monkong, S., Oratai, P., \& Laurel, L. (2013). Factors influencing quality of life among family caregivers of patients with advanced cancer: A causal model. Pacific Rim International Journal of Nursing Research, 17(4), 304-316.

Mellon, S., Northouse, L. L., \& Weiss, L. K. (2006). A population -based study of the quality life of cancer survivors and their family caregivers. Cancer Nursing, 29(2), 120-130.

Modi, A. C., Guilfoyle, S. M., \& Zeller, M. H. (2009). Impaired health-related quality of life in caregivers of youth seeking obesity treatment. Journal of Pediatric Psychology, 34(2), 147-155. doi:10.1093/jpepsy/jsn070 
Moon, H., \& Dilworth-Anderson, P. (2015). Baby boomer caregiver and dementia caregiving: Findings from the National Study of Caregiving. Age and Ageing, 44(2), 300-306. doi:10.1093/ageing/afu119

Mouzan, D. M. (2013). Can family relationships explain the race paradox? Journal of Marriage and Family, 75, 470-485.

Napoles, A. M., Chadiha, L., Eversley, R., \& Moreno-John, G. (2010). Reviews: Developing culturally sensitive dementia caregiver interventions: Are we there yet? American Journal of Alzheimer's Disease and Other Dementias, 25(5), 389406. doi:10.1177/1533317510370957

National Alliance for Caregiving. (2009). Caregiving in the U.S.: A focused look at the ethnicity of those caring for someone age 50 or older. Retrieved from http://www.caregiving.org/data/FINALRegularExSum50plus.pdf

National Alliance for Caregiving \& AARP. (2009). Executive summary: Caregiving in the U.S. . Retrieved from http://www.caregiving.org/pdf/research/Caregiving_in the US_2009 full_report. pdf

National Alliance for Caregiving \& AARP Public Policy Institute. (2015). Caregiver profile: The African American/Black caregiver. Retrieved from http://www.caregiving.org/wp-content/uploads/2015/05/Caregiving-in-the-US2015 AfricanAmerican_CGProfile.pdf

National Alliance for Caregiving and AARP Public Policy Institute. (2015). Caregiving in the U.S. Retrieved from http://www.caregiving.org/wpcontent/uploads/2015/05/2015 CaregivingintheUS_Final-Report-June4 WEB.pdf

National Cancer Institute. (2008). Cancer health disparities Retrieved from http://www.cancer.gov/about-nci/organization/crchd/cancer-health-disparitiesfact-sheet

National Coalition on Black Civic Participation: Black women's'roundtable. (2014).

Black women in the United States. Retrieved from https://www.washingtonpost.com/r/20102019/WashingtonPost/2014/03/27/NationalPolitics/Stories/2FinalBlackWomenintheUS2014.pdf

National Institute of Diabetes and Digestive and Kidney Diseases. (2014a). The kidneys and how they work. Retrieved from http://www.niddk.nih.gov/healthinformation/health-topics/Anatomy/kidneys-how-they-work/Pages/anatomy.aspx

National Institute of Diabetes and Digestive and Kidney Diseases. (2014b). Treatment methods for kidney failure: Hemodialysis. Retrieved from 
http://www.niddk.nih.gov/health-information/health-topics/kidneydisease/hemodialysis/Pages/facts.aspx

National Kidney Foundation. (2015). African Americans and kidney disease. Retrieved from https://www.kidney.org/news/newsroom/factsheets/African-Americans-and$\underline{\mathrm{CKD}}$

Nicoll, L. H., \& Beyea, S. C. (1999). Using secondary data analysis for nursing research. Association of Operating Room Nurses, 69(2), 428, 430, 433.

Noshad, H., Sadreddini, S., Nezami, N., Salekzamani, Y., \& Ardalan, M. R. (2009). Comparison of outcome and quality of life: Haemodialysis versus peritoneal dialysis patients. Singapore Medical Journal, 50(2), 185-192.

Nzerue, C. M., Demissachew, H., \& Tucker, J. K. (2002). Race and kidney disease: Role of social and environmental factors. Journal of the National Medical Association, 94(8), 28-38.

Obama, B. (2009). President Obama on health care reform at AMA [Press release]. Retrieved from http://www.whitehouse.gov/video/President-Obama-on-HealthCare-Reform-at-the-AMA

Office of Disease Prevention and Health Promotion. (2014a). Chronic kidney disease Retrieved from http://www.healthypeople.gov/2020/topicsobjectives/topic/chronic-kidney-disease

Office of Disease Prevention and Health Promotion. (2014b). Older adults. Retrieved from https://www.healthypeople.gov/2020/topics-objectives/topic/older-adults

Office of Research on Women's Health. (2014). Women of color health data book: The office on research on women's health National Institutes of Health Retrieved from http://orwh.od.nih.gov/resources/policyreports/pdf/WoC-Databook-FINAL.pdf

Office of Women's Health. (2012). Minority women's health: African Americans. Retrieved from http://www.womenshealth.gov/minority-health/african-americans/

Otis-Green, S., \& Juarez, G. (2012). Enhancing the social well-being of family caregivers. Seminars in Oncology Nursing, 28(4), 246-255. doi:10.1016/j.soncn.2012.09.007

Perreira, K. M., Deeb-Sossa, N., Harris, K. M., \& Bollen, K. (2005). What are we measuring? An evaluation of the CES-D across race/ethnicity and immigrant generation. Social Forces, 83(4), 1567-1601.

Pharr, J. R., Frances, C. D., Terry, C., \& Clark, M. C. (2014). Culture, caregiving, and health: Exlporing the influence of culture on family caregiving experiences. International Scholarly Resource Notices Public Health 2014(Article ID 689826), 8. 
Pickard, A. S., Johnson, J. A., Feeny, D. H., Shuaib, A., Carriere, K. C., \& Nasser, A. M. (2004). Agreement between patient and proxy assessments of health-related quality of life after stroke using the EQ-5D and Health Utilities Index. Stroke, 35(2), 607-612. doi:10.1161/01.STR.0000110984.91157.BD

Picot, S. J., Debanne, S. M., Namazi, K. H., \& Wykle, M. L. (1997). Religiosity and perceived rewards of Black and White caregivers. Gerontologist, 37(1), 89-101 $113 p$.

Pinquart, M., \& Sorensen, S. (2005). Ethnic differences in stressors, resources, and psychological outcomes of family caregiving: A meta-analysis. Gerontologist, 45(1), 90-106.

Pittman, L. (2012). African American families: Still a band of slaves? In S. Ahktar (Ed.), The African American Experience: Psychoanalytic Perspectives (pp. 229-270). Lanham, MD: Jason Aronson.

Pless, I. B., \& Satterwhite, B. (1973). A measure of family functioning and its application. Social Science \& Medicine, 7(8), 613-620.

Powe, B. D., Cooper, D. L., Kaw, C., \& Ross, L. (2013). Caregiver strain, quality of life, and symptom distress among dyads of African American cancer survivors and caregivers. Journal of Hospice \& Palliative Nursing, 15(5), 257-264.

Pressler, S. J., Gradus-Pizlo, I., Chubinski, S. D., Smith, G., Wheeler, S., Wu, J., \& Sloan, R. (2009). Family caregiver outcomes in heart failure. American Journal of Critical Care 18(2), 149-159. doi:10.4037/ajcc2009300

Prutkin, J. M., \& Feinstein, A. R. (2002). Quality of life measurements: Origin and pathogenesis. Yale Journal of Biology, 75, 79-93.

Radloff, L. S. (1977). The CES-D scale: A self-report depression scale for research in the general population. Applied Psychological Measurement, 1(385-401).

Rees, J., O'Boyle, C., \& MacDonagh, R. (2001). Quality of life: Impact of chronic illness on the partner. Journal of the Royal Society of Medicine, 94, 563-566.

Reinhard, S., Feinberg, L. F., Choula, R., \& Houser, A. (2015). Valuing the invaluable 2015 update: Undeniable progress, but big gaps remain. Retrieved from http://www.aarp.org/ppi/info-2015/valuing-the-invaluable-2015-update.html

Robison, J., Fortinsky, R., Kleppinger, A., Shugrue, N., \& Porter, M. (2009). A broader view of family caregiving: effects of caregiving and caregiver conditions on depressive symptoms, health, work, and social isolation. The Journals of Gerontology. Series B, Psychological Sciences and Social Sciences, 64(6), 788798. doi:10.1093/geronb/gbp015 
Rodrigue, J. R., \& Baz, M. A. (2007). Waiting for lung transplantation: Quality of life, mood, caregiving strain and benefit, and social intimacy of spouses. Clinical Transplantation, 21(6), 722-727. doi:10.1111/j.1399-0012.2007.00729.x

Rodrigue, J. R., Dimitri, N., Reed, A., Antonellis, T., Pavlakis, M., Johnson, S. R., \& Mandelbrot, D. A. (2010). Spouse caregivers of kidney transplant patients: quality of life and psychosocial outcomes. Progress in Transplantation, 20(4), 335-342.

Rodriguez-Sanchez, E., Perez-Penaranda, A., Losada-Baltar, A., Perez-Arechaederra, D., Gomez-Marcos, M. A., Patino-Alonso, M. C., \& Garcia-Ortiz, L. (2011). Relationships between quality of life and family function in caregiver. BioMed Central family practice, 12, 19. doi:10.1186/1471-2296-12-19

Roff, L. L., Burgio, L. D., Gitlin, L., Nichols, L., Chaplin, W., \& Hardin, J. M. (2004). Positive aspects of Alzheimer's caregiving: the role of race. The Journals of Gerontology. Series B, Psychological Sciences and Social Sciences, 59(4), P185190.

Roth, D. L., Perkins, M., Wadley, V. G., Temple, E. M., \& Haley, W. E. (2009). Family caregiving and emotional strain: associations with quality of life in a large national sample of middle-aged and older adults. Quality of Life Research, 18(6), 679-688. doi:10.1007/s11136-009-9482-2

Rozario, P. A., \& Menon, N. (2010). An examination of the measurement adequacy of the CES-D among African American women famiy caregivers. Psychiatry Research, 179, 107-112.

Sathvik, B. S., Parthasarathi, G., Narahari, M. G., \& Gurudev, K. C. (2008). An assessment of the quality of life in hemodialysis patients using the WHOQOLBREF questionnaire. Indian Journal of Nephrology, 18(4), 141-149. doi:10.4103/0971-4065.45288

Saunders, M. (2009). Indicators of health-related quality of life in heart failure family caregivers. Journal of Community Health Nursing, 26(4), 173-182. doi:10.1080/07370010903259196

Scharlach, A. E., Kellam, R., Ong, N., Baskin, A., Goldstein, C., \& Fox, P. J. (2006). Cultural attitudes and caregiver service use: Lessons from focus groups with racially and ethnically diverse family caregivers. Journal of Gerontological Social Work, 47(1-2), 133-156.

Schmidt, N. A., \& Brown, J. M. (Eds.). (2012). Evidence-based practice for nursing: Appraisal and application of research (2nd ed.): Jones \& Bartlett Learning.

Schulz, R., \& Beach, S. R. (1999). Caregiving as a risk factor for mortality: The caregiver health effects study. JAMA : The Journal of the American Medical Association, 282(23), 2215-2219. 
Schwartz, R. J., \& Panacek, E. A. (1996). Basics of research (Part 7): Archival data research. Air medical journal, 15(3), 119-124.

Scott, L. D. (2000). Caregiving and care receiving among a technologically dependent heart failure population. Advances in Nursing Science, 23(2), 82-97.

Semiatin, A., \& O’Connor, M. (2012). The relationship between self-efficacy and positive aspects of caregiving in Alzheimer's disease caregivers. Aging \& Mental Health, 16(6), 683-688 686p.

Shimoyama, S., Hirakawa, O., Yahiro, K., Mizumachi, T., Schreiner, A., \& Kakuma, T. (2003). Health-related quality of life and caregiver burden among peritoneal dialysis patients and their family caregivers in Japan. Peritoneal Dialysis International 23 Suppl 2, S200-205.

Siefert, M. L., Williams, A. L., Dowd, M. F., Chappel-Aiken, L., \& McCorkle, R. (2008). The caregiving experience in a racially diverse sample of cancer family caregivers. Cancer Nursing, 31(5), 399-407. doi:10.1097/01.ncc.0000305760.04357.96

Siegler, I. C., Brummett, B. H., Williams, R. B., Haney, T. L., \& Dilworth-Anderson, P. (2010). Caregiving, residence, race, and depressive symptoms. Aging \& Mental Health, 14(7), 771-778. doi:10.1080/13607861003713257

Singh, P., Germain, M. J., Cohen, L., \& Unruh, M. (2014). The elderly patient on dialysis: Geriatric considerations. Nephrology, Dialysis, Transplantation 29(5), 990-996. doi:10.1093/ndt/gft246

Smilkstein, G. (1978). The family APGAR: A proposal for a family function test and its use by physicians. The Journal of Family Practice, 6(6), 1231-1239.

Sohail, Z., Bailey, R., \& Richie, W. (2014). Misconceptions of depression in African Americans. Frontiers in Psychiatry, 5(65), 1-3. doi:doi: $10.3389 /$ fpsyt.2014.00065

Sok, S. R. (2010). Factors influencing life satisfaction of Korean older adults living with family. Journal of Gerontological Nursing, 36(3), 32-40. doi:10.3928/0098913420100202-01

Spencer, S. M., Goins, R. T., Henderson, J. A., Wen, Y., \& Goldberg, J. (2013). Influence of caregiving on health-related quality of life among American Indians. Journal of the American Geriatrics Society, 61(9), 1615-1620. doi:10.1111/jgs.12409

Spurlock, W. R. (2005). Spiritual well-being and caregiver burden in Alzheimer's caregivers. Geriatric Nursing, 26(3), 154-161. doi:10.1016/j.gerinurse.2005.03.006 
Sterba, K. R., Burris, J. L., Heiney, S. P., Ruppel, M. B., Ford, M. E., \& Zapka, J. (2014). "We both just trusted and leaned on the Lord": A qualitative study of religiousness and spirituality among African American breast cancer survivors and their caregivers. Quality of Life Research : An International Journal of Quality of Life Aspects of Treatment, Care and Rehabilitation, 23(7), 1909-1920. doi:10.1007/s11136-014-0654-3

Stevens, D. (2014). [Caregiver burden racial discrimination in African Americans: A mixed method study of chronic stress].

Talley, R. C., \& Crews, J. E. (2007). Framing the public health of caregiving. American Journal of Public Health, 97(2), 224-228. doi:10.2105/AJPH.2004.059337

Teschendorf, B., Schwartz, C., Ferrans, C. E., O'Mara, A., Novotny, P., \& Sloan, J. (2007). Caregiver role stress: When families become providers. Cancer Control, 14(2), 183-189.

The Council of Economic Advisors: Executive Office of the President of the United States. (2014). Nine facts about American families and work Retrieved from https://www.whitehouse.gov/sites/default/files/docs/nine_facts_about_family and _work real_final.pdf

The U.S. Equal Employment Opportunity Commission. (2011). Employee best practices for workers with caregiving responsibilities Retrieved from http://www.eeoc.gov/policy/docs/caregiver-best-practices.html

Tonelli, M., Wiebe, N., Bello, A., Klarenbach, S., Knoll, G., Jadhav, D., . . Gill, J. (2011). Systematic review: Kidney transplantation compared with dialysis in clinically relevant outcomes. American Journal of Transplantation, 11(10), 20932109.

Tong, A., Sainsbury, P., \& Craig, J. C. (2008). Support interventions for caregivers of people with chronic kidney disease: A systematic review. Nephrology Dialysis Transplantation, 23, 3960-3965.

Tsai, T. C., Liu, S. I., Tsai, J. D., \& Chou, L. H. (2006). Psychosocial effects on caregivers for children on chronic peritoneal dialysis. Kidney International, 70(11), 1983-1987. doi:10.1038/sj.ki.5001811

U.S. Bureau of Labor Statistic. (2016). Black women in the labor force. Retrieved from http://www.dol.gov/wb/media/Black_Women in the Labor_Force.pdf

United States Renal Data System. (2015). Annual Data Report: Epidemiology of kidney disease in the United States. Retrieved from Bethesda, MD: http://www.usrds.org/2015/view/v2 01.aspx

Wadhwa, D., Burman D., Swami N., Rodin G., Lo C., \& Zimmermann, C. (2013). Quality of life and mental health in caregivers of outpatients with advanced 
cancer. Psychooncology, 22(1099-1611 (Electronic)), 403-410.

doi:10.1002/pon.2104

Ware, J. E., Jr., \& Sherbourne, C. D. (1992). The MOS 36-item short-form health survey (SF-36). I. Conceptual framework and item selection. Medical Care, 30(6), 473483.

Warnecke, R. B., Ferrans, C. E., Johnson, T. P., Chapa-Resendez, G., O'Rourke, D. P., Chavez, N., . . Lad, T. (1996). Measuring quality of life in culturally diverse populations. Journal of the National Cancer Institute Monograph(20), 29-38.

Weiss, C. O., Gonzalez, H. M., Kabeto, M. U., \& Langa, K. M. (2005). Differences in amount of informal care received by non-Hispanic whites and latinos in a nationally representative sample of older Americans. Journal of the American Geriatrics Society, 53(1), 146-151. doi:10.1111/j.1532-5415.2005.53027.x

Wicks, M. N., Bolden, L., Mynatt, S., Rice, M. C., \& Acchiardo, S. R. (2007). INSIGHT potentially prevents and treates depressive and anxiety symptoms in black women caring for chronic hemodialysis recipients. Nephrology Nursing Journal, 34(6), 623-629.

Wicks, M. N., Milstead, E. J., Hathaway, D. K., \& Cetingok, M. (1997). Subjective burden and quality of life in family caregivers of patients with end stage renal disease. Nephrology Nursing Journal 24(5), 527-540 512p.

Wicks, M. N., Milstead, E. J., Hathaway, D. K., \& Cetingok, M. (1998). Family caregivers' burden, quality of life, and health following patients' renal transplantation. Journal of Transplant Coordination, 8(3), 170-176.

Wiedebusch, S., Konrad, M., Foppe, H., Reichwald-Klugger, E., Schaefer, F., Schreiber, V., \& Muthny, F. (2010). Health-related quality of life, psychosocial strains, and coping in parents of children with chronic renal failure. Pediatric Nephrology, 25(8), 1477-1485 1479p. doi:10.1007/s00467-010-1540-z

Wilson-Genderson, M., Pruchno, R., \& Cartwright, F. (2009). Effects of caregiver burden and satisfaction on affect of older end stage renal disease patients and their spouses. Psychology Aging, 24(4), 955-967. doi:10.1037/a0017368

Windle, P. E. (2010). Secondary data analysis: is it useful and valid? Journal of Perianesthesia Nursing, 25(5), 322-324. doi:10.1016/j.jopan.2010.07.005

Woods-Giscombe, C. L. (2010). Superwoman schema: African American women's views on stress, strength, and health. Qualitative Health Research, 20(5), 668-683. doi: $10.1177 / 1049732310361892$

World Health Organization. (1998). Programme on mental health: WHOQOL user manual. Retrieved from 
http://apps.who.int/iris/bitstream/10665/77932/1/WHO_HIS_HSI_Rev.2012.03_e ng.pdf

World Health Organization. (2012). Programme on mental health: WHOQOL user manual. Retrieved from http://apps.who.int/iris/bitstream/10665/77932/1/WHO_HIS_HSI_Rev.2012.03 e ng.pdf

Zarit, S. H., Reever, K. E., \& Bach-Peterson, J. (1980). Relatives of the impaired elderly: Correlates of feelings of burden. Gerontologist, 20(6), 649-655.

Zauszniewski, J. A., Bekhet, A. K., \& Suresky, M. J. (2009). Relationships among perceived burden, depressive cognitions, resourcefulness, and quality of life in female relatives of seriously mentally ill adults. Issues in Mental Health Nursing, $30(3), 142-150$.

Zauszniewski, J. A., Picot, S. J., Roberts, B. L., Debanne, S. M., \& Wykle, M. L. (2005). Predictors of resourcefulness in African American women. Journal of Aging and Health, 17(5), 609-633. doi:10.1177/0898264305279871

Zhang, A. Y., \& Gary, F. (2013). Discord of measurements in assessing depression among African Americans with cancer diagnoses. International Journal of Culture and Mental Health, 6(1), 58-71. doi:10.1080/17542863.2011.623042 


\title{
APPENDIX. INSTITUTIONAL REVIEW BOARD APPROVAL LETTER
}

\author{
- THE UNIVERSITY OF TENNESSEE \\ HEALTH SCIENCE CENTER
}

Institutional Review Board

910 Madison Avenue, Suite 600

Memphis, TN 38163

Tel: (901) 448-4824

26 April 2016

Shaquita Starks, MSN

UTHSC - CON - Nursing- Academic Programs

656 Doctors Office Building

66 North Pauline Street

Memphis, TN 38163

Re: 14-03087-XM

Study Title: Predictors of Quality of Life for African American Women Who Assist Persons Who Receive Dialysis [Award \#2T06SM060559-04]

Dear Dr. Starks:

The Administrative Section of the UTHSC Institutional Review Board (IRB) reviewed your application for revision of your previously approved project, referenced above. The IRB determined that your revision application is eligible for expedited review under 45 CFR 46.110(b)(2), and that your study remains eligible for exempt status under 45 CFR 46.102(f), in that it does not involve "human subjects" as defined therein. The attached revisions to your project were approved as complying with proper consideration of the rights and welfare of human subjects.

In the event that volunteers, either subjects or patients, are to be recruited by means other than usual and standard patient care practices, the Board must approve of any such solicitation materials (i.e., advertising copies or posters, etc.)

Any alterations (revisions) in the research project must be submitted to and approved by the UTHSC Institutional Review Board prior to implementation of these revisions.

Sincerely,

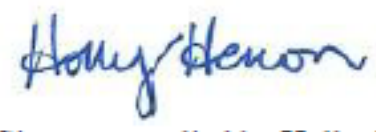

Signature applied by Holly A Herron on 04/26/2016 01:25:40 PM CDT

Holly A Herron, BA, CIM

IRB Administrator

UTHSC IRB 
Page 2 of 2

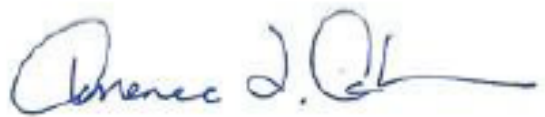

Terrence F Ackerman, $\mathrm{PhD}$

Chairman

UTHSC IRB

Attachment: Revisions

1. The study application was updated to Version 1.3 to incorporate:

a. Revising the study title

b. Updating the funding source

c. Removing Aim 5

d. Updating the statistical software to SPSS v. 22

e. Revising the study procedures to include One-way ANOVA, Independent t-test, and Pearsons' $r$

f. Converting to the newest application format

2. In accord with 45 CFR 46.116 (d), informed consent is waived. 


\section{VITA}

Shaquita Antoinette Starks was born in Greenwood, Mississippi in 1977. She graduated from Grenada High School in Grenada, Mississippi where she was raised. She received her Associate Degree in Nursing from Holmes Community College in Grenada, Mississippi in 1998. She received her Bachelor of Science in Nursing and a Master of Science in Nursing from The University of Tennessee Health and Science Center in Memphis, Tennessee in 2006 and 2007, respectively. She has been certified as a Family Nurse Practitioner with ANCC since February 2008. She has over 17 years' experience as a nurse. She has been employed of many areas of nursing including community health, medical surgical nursing, chronic in-patient hemodialysis, acute hemodialysis and peritoneal dialysis, gastroenterology, pediatric hemodialysis, pediatric emergency, geriatrics, psychiatric mental health nursing, retail health. She has been employed as an adjunct faculty instructor and has taught courses in nursing research, health assessment, and ethical dialogue. She has provided research support as a consultant for a NIH funded study and as a community health consultant for a program that addressed health disparities in African Americans.

She is eligible for certification as a Psychiatric Mental Health Nurse Practitioner with ANCC. She is a contributing author on one unpublished manuscript and has presented at both local, state, and regional conferences and meetings.

Shaquita A. Starks received a Doctor of Philosophy in nursing degree from the College of Graduate Health Sciences at The University of Tennessee Health Science Center in May 2016. Her dissertation research focused on Predictors of Quality of Life of African American women who are Caregivers of Persons with End Stage Renal Disease. Presently she is employed at CVS Minute Clinic and works as an Independent Contractor at various community mental health facilities in the Memphis metropolitan area.

While a doctoral student at UTHSC, Shaquita was selected as a SAMHSA Minority Fellow with SAMHSA/ANA for two consecutive years. Through this fellowship she was a lead author on four presentations that described predictors of quality of life. She had edited manuscripts written by several authors. 